Journal for ImmunoTherapy of Cancer

\section{Interleukin-30 feeds breast cancer stem cells via CXCL10 and IL23 autocrine loops and shapes immune contexture and host outcome}

\author{
Carlo Sorrentino, ${ }^{1,2}$ Stefania Livia Ciummo, ${ }^{1,2}$ Luigi D'Antonio, ${ }^{1,2}$ \\ Cristiano Fieni (D) , , ${ }^{1,2}$ Paola Lanuti, ${ }^{1}$ Alice Turdo, ${ }^{3}$ Matilde Todaro, ${ }^{3}$ \\ Emma Di Carlo (i) ${ }^{1,2}$
}

To cite: Sorrentino C, Ciummo SL, D'Antonio L, et al. Interleukin-30 feeds breast cancer stem cells via CXCL10 and IL23 autocrine loops and shapes immune contexture and host outcome. Journal for ImmunoTherapy of Cancer 2021;9:e002966. doi:10.1136/ jitc-2021-002966

\section{- Additional supplemental} material is published online only. To view, please visit the journal online (http://dx.doi.org/10. 1136/jitc-2021-002966).

CS and SLC contributed equally.

CS and SLC are joint first authors.

Accepted 09 September 2021

Check for updates

(c) Author(s) (or their employer(s)) 2021. Re-use permitted under CC BY-NC. No commercial re-use. See rights and permissions. Published by BMJ.

For numbered affiliations see end of article.

Correspondence to Professor Emma Di Carlo; edicarlo@unich.it

\section{ABSTRACT}

Background Breast cancer (BC) progression to metastatic disease is the leading cause of death in women worldwide. Metastasis is driven by cancer stem cells (CSCs) and signals from their microenvironment. Interleukin (IL) 30 promotes $\mathrm{BC}$ progression, and its expression correlates with disease recurrence and mortality. Whether it acts by regulating BCSCs is unknown and could have significant therapeutic implications.

Methods Human (h) and murine (m) BCSCs were tested for their production of and response to IL30 by using flow cytometry, confocal microscopy, proliferation and sphereformation assays, and PCR array. Immunocompetent mice were used to investigate the role of BCSC-derived IL30 on tumor development and host outcome. TCGA PanCancer and Oncomine databases provided gene expression data from 1084 and $75 \mathrm{hBC}$ samples, respectively, and immunostaining unveiled the BCSC microenvironment. Results hBCSCs constitutively expressed IL30 as a membrane-anchored glycoprotein. Blocking IL30 hindered their proliferation and self-renewal efficiency, which were boosted by IL30 overexpression. IL30 regulation of immunity gene expression in human and murine BCSCs shared a significant induction of IL23 and CXCL10. Both immunoregulatory mediators stimulated BCSC proliferation and self-renewal, while their selective blockade dramatically hindered IL30-dependent BCSC proliferation and mammosphere formation. Orthotopic implantation of IL30-overexpressing mBCSCs, in syngeneic mice, gave rise to poorly differentiated and highly proliferating $\mathrm{MYC}^{+} \mathrm{KLF}^{+} \mathrm{LAG3}^{+}$tumors, which expressed CXCL10 and IL23, and were infiltrated by myeloid-derived cells, Foxp $3^{+} \mathrm{T}$ regulatory cells and NKp46 ${ }^{+} \mathrm{ROR} \gamma \mathrm{t}^{+}$type 3 innate lymphoid cells, resulting in increased metastasis and reduced survival. In tumor tissues from patients with $\mathrm{BC}$, expression of IL30 overlapped with that of CXCL10 and $I L 23$, and ranked beyond the 95th percentile in a Triple-Negative enriched BC collection from the Oncomine Platform. CIBERSORTx highlighted a defective dendritic cell, $\mathrm{CD} 4^{+} \mathrm{T}$ and $\gamma \delta \mathrm{T}$ lymphocyte content and a prominent LAG3 expression in IL30 ${ }^{\text {high }}$ versus IL30 ${ }^{\text {low }}$ human BC samples from the TCGA PanCancer collection.

Conclusions Constitutive expression of membrane-bound IL30 regulates BCSC viability by juxtacrine signals and via second-level mediators, mainly CXCL10 and IL23. Their autocrine loops mediate much of the CSC growth factor activity of IL30, while their paracrine effect contributes to IL30 shaping of immune contexture. IL30-related immune subversion, which also emerged from computational analyses, strongly suggests that targeting IL30 can restrain the BCSC compartment and counteract BC progression.

\section{BACKGROUND}

Breast cancer (BC) is the leading cancer killer among women worldwide. ${ }^{1}$ Mortality is due to metastatic disease for which there is no effective cure. Metastasization is driven by a small population of cancer stem cells (CSCs), which are prevalent in BCs with a worse prognosis, ${ }^{2}$ and may contribute to their propensity for metastasis and chemotherapy resistance. ${ }^{3}$ Signals regulating CSC entry or exit from the steady-state condition are fundamental in shaping BC behavior and patient outcome. ${ }^{3}$ The immunoregulatory molecule, interleukin (IL) 30, has been found in murine (m) prostate cancer (PC) stem-like cells (SLCs) and has revealed autocrine and paracrine effects in the PC stem cell niche microenvironment and a critical role in $\mathrm{PC}$ onset and progression. ${ }^{45}$ Targeting IL30 signaling in PC-SLCs and host environment has proven to counteract PC growth and improve host survival. ${ }^{5}$

Discovered in 2002 and identified as the p28 subunit of the heterodimeric cytokine IL27, ${ }^{6}$ which has demonstrated antitumor effects, ${ }^{7-9}$ IL30 can act as a self-standing cytokine, endowed with its own functional properties, ${ }^{10-12}$ that signals via IL6 Receptor Subunit Alpha (IL6R) by recruiting a gp130 homodimer. ${ }^{13}$

In PC and BC, IL30 is produced by cancer and leukocytes infiltrating the tumor or draining lymph nodes (LNs), particularly in the high grade and stage of disease. ${ }^{1415}$ In human BC cells, IL30 boosts, via STAT1/ 
STAT3 signaling, a broader program of proliferation, invasive migration and inflammatory milieu and induces cancer cell expression of MYC and SHH, which are fundamental in the maintenance of a putative CSC compartment. ${ }^{16}{ }^{17}$ In patients with BC, high levels of IL30, in tumor and draining LNs, have been associated with recurrence and correlated with mortality at multivariate analyses. ${ }^{15}$ The lack of IL30 in the tumor microenvironment has proved effective in inhibiting the growth and progression of Triple-Negative (TN) BC, ${ }^{18}$ the molecular subtype with the highest CSC content. ${ }^{19}$

In the present study, we provide evidence that human and murine BCSCs are both the source and target of IL30, and identify the second-level mediators induced by IL30 in BCSCs and their impact on CSC behavior, immunological context, and host outcome.

\section{MATERIALS AND METHODS}

\section{Cell cultures and MTT assay}

Human (h) BCSCs, BCSC-608 and BCSC-105, were generated and provided by Professor G Stassi (University of Palermo, Italy), who characterized them as CSCs, which grew in spheres and reproduced, in immunocompromised host, the tumor of origin. ${ }^{20}$ Both cell lines were authenticated by surface staining for characteristic markers, as described. ${ }^{20}$

Murine (m) BCSCs, Py230 cells, were derived from a mammary tumor spontaneously arisen in a MMTV-PyMT (mouse mammary tumor virus promoter driven Polyoma middle T-antigen) transgenic female C57BL/6J mouse, and were identified as CSCs, which grew in spheres and reproduced the parental tumor, when implanted as a single cell into syngeneic host. ${ }^{21}$ mBCSCs were purchased from ATCC (ATCC Cat\# CRL-3279, RRID:CVCL_AQ08) and authenticated by Short-Tandem Repeat profiling.

Murine (m) BC cells, E0771 mammary adenocarcinoma cell line (RRID:CVCL_GR23), were derived from a spontaneous mammary tumor developed in a female C57BL/6J mouse, ${ }^{22}$ and were characterized as TripleNegative and Basal-like. ${ }^{23}$ E0771 cells were purchased from CH3BioSystems (Amherst, NY, USA) and authenticated by Short-Tandem Repeat profiling.

All cell lines were passaged for fewer than 6 months after resuscitation and were confirmed mycoplasma-free by PCR analysis.

Cell proliferation was assessed using the CellTiter 96 AQueous One Solution Cell Proliferation Assay (\#G3582; Promega, Madison, WI, USA), according to manufacturer's instructions, as described in the online supplemental materials and methods.

\section{Flow cytometry}

To assess phenotype markers, BCSCs were harvested and mechanically dissociated into a single cell suspension. The cells were pelleted, suspended in PBS and incubated, for $30 \mathrm{~min}$ at $4^{\circ} \mathrm{C}$, with the antibodies (Abs) listed in online supplemental table S1, at a concentration of
$0.25 \mu \mathrm{g} / 100 \mu \mathrm{l}$. Acquisition was performed using a BD Scientific Canto II Flow Cytometer (RRID:SCR_018056) and the data were analyzed using FlowJo software (FlowJo, RRID:SCR_008520). Dead cells were excluded by 7AAD staining. All experiments were performed in triplicate.

\section{Transfection with IL27p28 (IL30) expressing vector}

Creation of IL30 lentiviral expression vector, and its transfection into Py230 cells, were performed as described in online supplemental materials and methods. Expression of IL30 was confirmed by real-time RT-PCR, Western blotting (WB) and ELISA.

For transient overexpression of human IL30 in BCSC608, we used the IL27 Human Tagged ORF Clone (\#RC209337L1; Origene, Rockville, MD, USA), which was transfected in BCSC-608 cells using Lipofectamine 3000 Reagent (\#L3000001; Thermo Fisher Scientific, Waltham, MA, USA). Overexpression of IL30 was confirmed by realtime RT-PCR and WB.

\section{IL30 gene silencing}

IL30 silencing in hBCSCs was achieved by using the Human shRNA Plasmid Kit (\#TR303941; Origene, Rockville, MD, USA). Non-effective scrambled ( $\mathrm{Scr}$ ) shRNA was used as control. Downregulation of IL30 expression was confirmed by real-time RT-PCR and WB.

\section{PCR array and real-time RT-PCR}

PCR array and real-time RT-PCR were performed, as described in online supplemental materials and methods. Expression of human and murine inflammation and immunity genes, listed in online supplemental tables S2,S3, was investigated in IL30 overexpressing or silenced human and murine BCSCs.

\section{Enzyme-linked immunosorbent assay}

Quantitation of IL30, CXCL10, IL23, CXCL1 and CSF2, in the supernatant derived from murine or human BCSCs, was carried out as described in online supplemental materials and methods.

\section{Western blotting}

Western blot (WB) was performed to assess IL30 overexpression in mBCSCs and IL30 overexpression or silencing in hBCSCs, as described in the online supplemental materials and methods.

\section{Sphere formation assay}

The sphere-formation efficiency, and the associated selfrenewal ability, of murine and human BCSC cells was assessed by using the Extreme Limiting Dilution Analysis (ELDA, RRID:SCR_018933), ${ }^{24}$ as described in online supplemental materials and methods.

\section{Mouse studies}

The tumorigenicity of mBCSCs was assessed, by limiting dilution analysis, by Bao and coworkers. ${ }^{21}$ Experimental conditions for tumor growth were determined after orthotopic implantation, in $C 57 B L / 6 \mathrm{~J}$ mice 
(RRID:IMSR_JAX:000664, purchased from Envigo, Indianapolis, IN, USA), of different dilutions of mBCSCs, and after the assessment of the tumor microenvironment and latency times, as reported in online supplemental materials and methods and figure $\mathrm{S} 1$.

Finally, three groups of forty-five 8 week old mice were subcutaneously injected with $1 \times 10^{4}$ wild-type (CTRL) mBCSCs, Empty Vector (EV) or IL30 lentiviral-DNA (IL30LV-DNA) transfected mBCSCs, also referred to as IL30mBCSCs. Based on tumor growth and progression rate, 15 mice from each group were euthanized at key time points ( 3 mice per point) for histopathological and molecular analyses. The remaining 30 mice per group were kept until tumors reached $1000 \mathrm{~mm}^{3}$ or evidence of suffering was observed. Autopsy and histopathological examinations of the different organs (liver, lungs and spleen) were performed. With an overall sample size of 30 mice per group, a one-sided log-rank test detected a difference of $30 \%$ in tumor growth between two groups, with a $90 \%$ power, at a 0.05 significance level $\left(\mathrm{G}^{*}\right.$ Power, RRID:SCR_013726). ${ }^{25}$

For the experimental metastasis assay, three groups of 30 $C 57 B L / 6 \mathrm{~J}$ mice were injected, into the tail vein, with $5 \times 10^{4}$ mBCSCs, EVmBCSCs or IL30mBCSCs. Mice were sacrificed 40 days after tumor cell injection and the lungs were analyzed for the presence of metastases. Briefly, formalinfixed lungs were cut into transverse slices, embedded in paraffin and subjected to semiserial $3 \mu \mathrm{m}$ sections. H\&Estained sections were histopathologically analysed, for the presence of spontaneous or experimental metastasis, under a light microscope (DMLB light microscope; Leica Microsystems, Wetzlar, Germany).

\section{Patients and samples}

Thirty-two tumor samples classified as Triple-Negative BCs, according to the St. Gallen International Expert Consensus in 2011, were obtained from the Anatomic Pathology Department of the "S.S. Annunziata Hospital", Chieti, Italy, after written informed consent from patients. Patients' clinicopathological characteristics are shown in online supplemental table S4. This sample size allows to detect, with an $80 \%$ power, a difference of $10 \%$ in the number of CXCL10 (or IL23) positive cells/total number of $\mathrm{CD}_{133^{+}} \mathrm{IL}^{2} 0^{+}$cells per field, at a 0.05 significance level. $^{26}$

\section{Histopathology, immunohistochemistry and confocal microscopy}

Histology, immunohistochemistry and confocal microscopy were performed as described in online supplemental materials and methods, using the antibodies listed in online supplemental table S5.

Proliferation index, microvessel and cell counts were assessed by light microscopy (DMLB light microscope; Leica Microsystems), at $\times 400$ in an $85,431.59 \mu^{2}$ field, on single or triple (CD133/IL30/CXCL10 or IL23) immunostained sections, using QWin image analysis software (Leica QWin, RRID:SCR_018940). Six to eight high-power fields were analyzed for each section and three sections per sample were evaluated. Results were expressed as mean $\pm \mathrm{SD}$ of positive cells per field (F4/80, CD11b, Foxp3, CD3, Ly-6G, CD4, CD8, NKp46/ROR $\gamma \mathrm{t}$ ), or mean percentage $\pm \mathrm{SD}$ of positive cells/number of total cells per field (PCNA, MYC, KLF4), or mean percentage \pm SD of CXCL10 or IL23 positive cells/total number of $\mathrm{CD} 133^{+} \mathrm{IL} 30^{+}$cells per field. Microvessels were identified as small tubes or circles marked by CD31 Abs and results were expressed as mean \pm SD of positive vessels/field. Each slide was analyzed by two independent investigators, in a blind fashion, and there was an almost perfect agreement (kappa value $=0.82$ ) between their evaluations.

\section{Bioinformatic analyses}

For bioinformatic analyses (cBioPortal, RRID:SCR_014555), gene expression data from the "Breast Invasive Carcinoma TCGA PanCancer collection" dataset, ${ }^{27}$ which includes 1084 BC cases, and from Waddell's database, which predominantly contains TNBCs (26 out of 75 cases), were downloaded from the cBioportal for Cancer Genomics database (https://www.cbioportal.org; cBioPortal, RRID:SCR_014555) and Oncomine website (https://www.oncomine.org; Oncomine Research Platform, RRID:SCR_007834), respectively. For each sample, the Z-scores of gene expression levels were calculated, compared with the mean of all samples in the study, and all samples with a Z-score $\geq 2$ were considered overexpressing. Subsequently, we selected only the cases for which information regarding the tumor subtype was available, and assessed the association between gene expression and BC subtypes using Fisher's exact test. The correlation between gene expressions was assessed using Spearman's rank correlation coefficient $(\rho)$. The Cancer Outlier Profile Analysis (COPA) on Waddell's database was performed using the data analysis tool included in the Oncomine Platform.

To estimate the tumor-infiltrating immune cell content in BC samples, transcripts per million-normalised RNAseq data of the "Breast Invasive Carcinoma TCGA PanCancer collection" were downloaded from http://firebrowse.org and analyzed using CIBERSORTx,${ }^{28}$ a computational framework, which accurately infers cell type abundance from the RNA profiles of tissue samples, using specific gene signatures. LM22 was used as signature matrix that contains 547 genes, which distinguish 22 human hematopoietic cell phenotypes, ${ }^{29}$ and batch correction option was enabled to remove technical differences between the signature matrix and RNA-seq data. Results were converted in .xlsx file format, and between-group differences were assessed by Student's t-test.

All statistical tests were evaluated at an $\alpha$ level of 0.05 .

\section{Statistical analysis}

For in vitro and in vivo studies, between-group differences were assessed by Student's t-test, or ANOVA, followed by Tukey HSD test. Between-group differences 
in sphere-forming potential were evaluated by ELDA. ${ }^{24}$ Survival curves were constructed using the Kaplan-Meier method and survival differences were analyzed by the logrank test. All statistical tests were evaluated at an $\alpha$ level of 0.05 using Stata V.13 (StataCorp, College Station, TX, USA; RRID:SCR_012763).

\section{RESULTS \\ IL30 promotes the viability and mammosphere forming ability of BCSCs}

To explore IL30's impact on human (h) and murine (m) BCSC behavior, we first investigated whether they expressed the IL30 receptor (R) and produced the cytokine.

hBCSCs, referred to as BCSC-608 and BCSC-105, were isolated from invasive ductal adenocarcinomas and are endowed with the functional properties of CSCs. ${ }^{20}$ mBCSCs, Py230, were isolated from a spontaneously arising tumor in MMTV-PyMY transgenic mouse and identified as multipotent mammary CSCs. ${ }^{21}$ To exclude differentiated cells, human and murine BCSCs were phenotypically validated by flow cytometry. hBCSCs displayed a $\mathrm{CD} 24^{+} \mathrm{CD} 29^{+} \mathrm{CD} 117^{+} \mathrm{CD} 133^{+}$phenotype and mBCSCs were characterized by a CD24 $4^{+} \mathrm{CD} 44^{+} \mathrm{CD} 49 \mathrm{f}^{+}$ phenotype (online supplemental figure S2). Both human and murine BCSCs expressed the two IL30R chains, ${ }^{11} 14$ IL6R $\alpha$ (CD126) and gp130 (CD130) (figure 1A).

IL30 was undetectable, by ELISA, in the supernatant of hBCSCs. Unlike its murine counterpart, which is secreted as a soluble mediator, hIL30 (IL27p28 subunit, or IL27 $\alpha$ ) is not released, unless it heterodimerizes with a $\beta$-subunit (EBI3 or Cytokine-Like Factor 1) or a molecular mechanism, which affects protein folding, determines protein secretion. ${ }^{30}$

However, analysis of its peptide sequence, with PSIPRED (Department of Computer Science, University College of London; figure 1B,C), revealed the presence of a stretch of 16 residues toward the carboxy-terminus of the protein, made up of $75 \%$ hydrophobic amino acids, which is predictive of a single-pass type I transmembrane helix. Flow cytometry (figure 1D), WB analyses (which discriminated the cytoplasmic and plasma membrane protein fractions; see CTRL cells in figure $1 \mathrm{E}, \mathrm{F}$ ) and confocal microscopy (which showed IL30 co-localization with $\mathrm{Na}^{+} \mathrm{K}^{+}$-ATPase ${ }^{31}$ (figure 1G,H), demonstrated that IL30 localized in the plasma membrane of hBCSCs.

IL30 overexpression, via gene transfection, in both BCSC-608 and BCSC-105 (figure 1I,J), confirmed the localization of IL30 in the cell membrane (figure 1E,F) and significantly increased BCSC proliferation (ANOVA: $\mathrm{p}=0.03$ and $\mathrm{p}=0.001$, respectively; figure $1 \mathrm{~K}, \mathrm{~L})$. By contrast, the blockade of constitutively produced IL30, by specific neutralizing Abs, significantly decreased the proliferation (Student's t-test, $\mathrm{p}=0.0006$ ) (figure 1M,N) and mammosphere-forming capability of both hBCSCs $\left(\chi^{2}\right.$ test, $\mathrm{p}<0.05$ ) (figure $1 \mathrm{O}, \mathrm{P}$ and $\mathrm{Q}$ ), an effect that could not be ascribed to the blockade of IL27, since IL30 was undetectable in the supernatants.

Considering that IL30 was neither produced nor released by mBCSCs, as assessed by ELISA, we transfected them with the IL30 gene and generated a clone, namely IL30mBCSC (figure 1R,S), that released $20.25 \mathrm{ng} / \mathrm{mL}$ of IL30. Both IL30mBCSCs, and wild-type mBCSCs treated with rIL30 $(50 \mathrm{ng} / \mathrm{mL})$, showed a higher proliferation rate (ANOVA: $\mathrm{p}<0.0001$; Tukey HSD test, $\mathrm{p}<0.01$ ) (figure $1 \mathrm{~T}$ ) and mammosphere-forming efficiency $\left(\chi^{2}\right.$ test, $\left.\mathrm{p}<0.05\right)$ (figure $\left.1 \mathrm{U}\right)$ when compared with EVmBCSCs and mBCSCs (CTRL), respectively. The addition of neutralizing anti-IL30 Abs to the culture medium of IL30-overexpressing mBCSCs consistently decreased both their proliferation (ANOVA: $\mathrm{p}<0.0001$; Tukey HSD test, $\mathrm{p}<0.01)$ and mammosphere formation efficiency $\left(\chi^{2}\right.$ test, $\mathrm{p}<0.05$ ) (figure $1 \mathrm{~T}, \mathrm{U}$ ).

\section{Human "membrane-bound" and murine "secreted" IL30 shapes immunity gene expression profiles of BCSCs that share a strong upregulation of CXCL10 and IL23}

To assess whether IL30 affects BCSC-host immunity interactions, we first analyzed the inflammation and immunity gene expression profile of BCSC-608, which among hBCSCs had the highest level of constitutive IL30 expression (figure 1D), after IL30 gene silencing and overexpression. Changes in the expression level of membrane-bound IL30, obtained by IL30 gene silencing and overexpression in hBCSC-608, were proved at the transcriptional (figure 1I) and protein level by WB (figures $1 \mathrm{E}$ and $2 \mathrm{~A}$ ), flow cytometry (figure 2B) and confocal analyses (figure $2 \mathrm{C}, \mathrm{D}$ and $\mathrm{E}$ ).

IL30-overproduction by hBCSCs stimulated their expression of cytokines and immune regulatory mediators (figure 2F), such as IL1B (2.87 times), TNFA (3.15 times) and, especially, of CSF2 (67.41 times) and IL23A (36.12 times), whereas the expression of HLA-A (-2.88 times), IL10 (-3.11 times), IL12A (-2.47 times) and IL15 $(-3.57$ times) were inhibited. hIL30 overproduction by hBCSCs also promoted the expression of genes coding for chemokines, such as CCL4 (3.69 times), CXCL1 (15.83 times), CXCL8 (2.86 times) and CXCL10 (5.57 times). By contrast, hIL30 silencing downregulated CXCL10 (-3.12 times), PTGS2 (-3.14 times) and IL1B (-241.7 times), together with chemokines and chemokine receptors, CCL5 (-3.34 times), CCL28 (-2.15 times), CXCL11 ( -4.83 times), CCR2 (-2.21 times), CXCR2 (-3.01 times) and CXCR4 (-3.2 times). Expression of NOS2 (-2.15 times), PDL2 (-2.76 times) and, primarily, STAT3 (-21.41 times) was also downregulated in hBCSCs by hIL30 silencing.

Assessment of the most highly upregulated mediators, specifically CSF2 and CXCL1, in the supernatant of IL30-overexpressing BCSC-608 confirmed their substantial increase at the protein level (CSF2: $20.57 \pm 0.56 \mathrm{pg}$ / $\mathrm{mL}$ in IL30-over, versus $8.62 \pm 1.73 \mathrm{pg} / \mathrm{mL}$ in $\mathrm{EV}$, and $8.46 \pm 0.70 \mathrm{pg} / \mathrm{mL}$ in CTRL cells. ANOVA: $\mathrm{p}<0.0001$; Tukey HSD test: $\mathrm{p}<0.01$ versus both EV and CTRL cells) (CXCL1: $8.41 \pm 1.26 \mathrm{pg} / \mathrm{mL}$ in IL30-over, versus $3.91 \pm 1.57 \mathrm{pg} / \mathrm{mL}$ in 


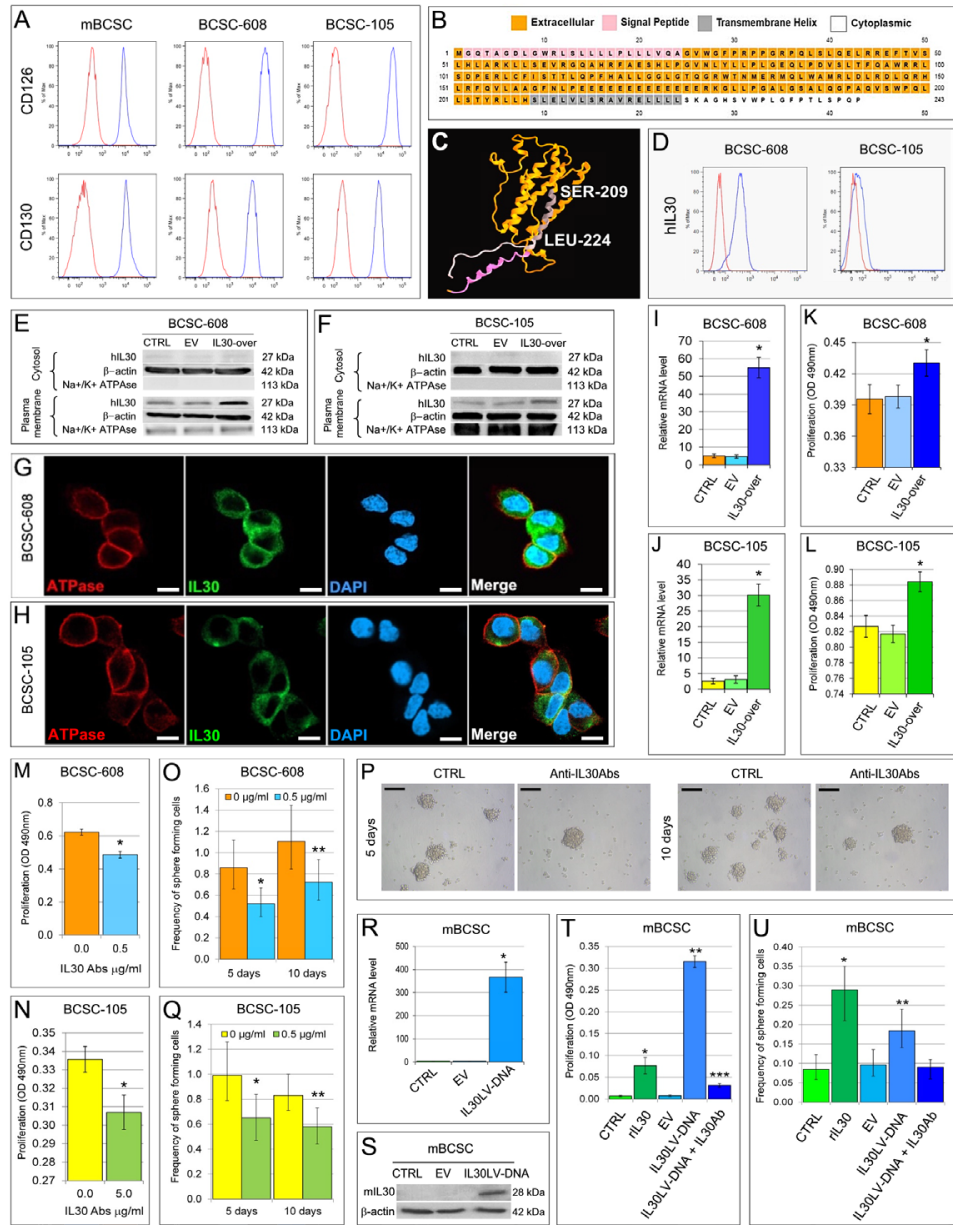

Figure 1 Expression of IL30 receptor in breast cancer stem cells (BCSCs) and their response to IL30 treatment. (A) Cytofluorimetric analyses of gp130 (CD130) and IL6R $\alpha$ (CD126) expression in human and murine BCSCs. Red lines: isotype control. Blue lines: specific Abs. Experiments were performed in triplicate. (B) Amino acid sequence and (C) tertiary structure of hIL30 protein. The extracellular portion is shown in orange, the signal peptide is shown in pink, the transmembrane helix is shown in gray (starting with the serine residue at position 209 and ending with the leucine residue at position 224) and the cytoplasmic portion is shown in white. (D) Cytofluorimetric analyses of IL30 expression in hBCSCs. The BCSC-608 cells showed a mean fluorescence intensity (MFI) ratio of 8.5 whereas BCSC-105 cells showed a MFI ratio of 2.3. The MFI was obtained calculating the ratio between the fluorescence of the samples and their isotype controls. Red lines: isotype control. Blue lines: anti-IL30 Abs. Experiments were performed in triplicate. (E, F) Western blot analyses of IL30 protein expression in the cytosolic and plasma membrane fractions of wild-type (CTRL), EV and IL30 gene transfected (IL30-over) BCSC-608 (E) and BCSC-105 (F). (G, H) Confocal microscopy analyses of BCSC-608 (G) and BCSC-105 (H) highlights in green the plasma membrane expression of IL30 that co-localizes with the red-stained $\mathrm{Na}^{+} \mathrm{K}^{+}$-ATPase, and in blue the nuclei, stained with 4'-6-diamidino-2phenylindole (DAPI). Magnification: $\times 400$. Scale bars: $6 \mu \mathrm{m}$. (I, J) Relative expression \pm SD of $I L 30 \mathrm{mRNA}$ in wild-type (CTRL), EV and IL30 gene transfected (IL30-over) BCSC-608 (I) and BCSC-105 (J). ANOVA, $p<0.0001$. * ${ }^{*}<0.01$, Tukey HSD test compared with CTRL and EV-hBCSCs. (K, L) MTT assay of IL30 gene transfected (IL30-over) BCSC-608 (K) and BCSC-105 (L) versus EVtransfected and CTRL cells. ANOVA, $p<0.05$. ${ }^{*} p<0.05$, Tukey HSD test compared with CTRL and EVhBCSCs. (M, N) MTT assay of BCSC-608 (M) and BCSC-105 (N), after 48 hours of treatment with anti-IL30Abs (BCSC-608: 0.5 $\mathrm{gg} / \mathrm{mL}$ and BCSC-105: $5 \mu \mathrm{g} /$ $\mathrm{mL}$ ). *Student's t-test: $p<0.05$. (O) Sphere-forming assay, evaluated by ELDA, of BCSC-608 after 5 and 10 days of treatment with anti-IL30Abs $(0.5 \mu \mathrm{g} / \mathrm{mL}) .{ }^{*} p=0.00489, \chi^{2}$ test compared with untreated cells. ${ }^{* *} p=0.021, \chi^{2}$ test compared with untreated cells. (P) BCSC-608-derived spheres were dissociated, seeded at concentrations of 1 cell/well, and untreated (CTRL, pictures on the left) or treated with anti-IL30 Abs $(0.5 \mu \mathrm{g} / \mathrm{mL}$ ) (pictures on the right). Magnification: $\times 400$. Scale bars: $100 \mu \mathrm{m}$. (Q) Sphereforming assay, evaluated by ELDA, of BCSC- 105 after 5 and 10 days of treatment with anti-IL30Abs $(0.5 \mu \mathrm{g} / \mathrm{mL})$. ${ }^{*} \mathrm{p}=0.00374, \chi^{2}$ test compared with untreated cells. ${ }^{\star *} \mathrm{p}=0.012, \chi^{2}$ test compared with untreated cells. (R) Relative expression $\pm S D$ of $/ / 30$ mRNA in I/30 gene transfected (IL30LV-DNA) mBCSCs, that is, IL30mBCSCs. ANOVA, $p<0.0001 .{ }^{*} p<0.01$, Tukey HSD test compared with wild-type (CTRL) and EVmBCSCs. (S) Western blot analysis of IL30 protein expression in CTRL, EV and IL30mBCSCs (IL30LV-DNA). (T) MTT assay of mBCSCs after 48 hours of treatment with rlL30 (50 ng/mL), and of IL30mBCSCs (IL30LV-DNA) with and without anti-IL30 Abs. ANOVA, $p<0.0001$. ${ }^{*} p<0.01$, Tukey HSD Test versus CTRL, EV, IL30LV-DNA and IL30LV-DNA + IL30 Abs. ${ }^{* *} \mathrm{p}<0.01$, Tukey HSD test versus CTRL, rlL30, EV and IL30LV-DNA + IL30 Abs. ${ }^{* * *} \mathrm{p}<0.05$, Tukey HSD test versus CTRL, rIL30, EV and IL30LV-DNA. (U) Sphere-forming assay, evaluated by ELDA, of mBCSCs after 15 days of culture with rlL30 $(50 \mathrm{ng} / \mathrm{mL})$, and of IL30mBCSCs (IL30LV-DNA) with and without anti-IL30 Abs. ${ }^{*} \mathrm{p}<0.05, \chi^{2}$ test versus CTRL, EV and IL30LVDNA + IL30 Abs. ${ }^{* *} \mathrm{p}<0.05, \chi^{2}$ test versus CTRL, EV and IL30LV-DNA + IL30 Abs. Experiments were performed in triplicate. 

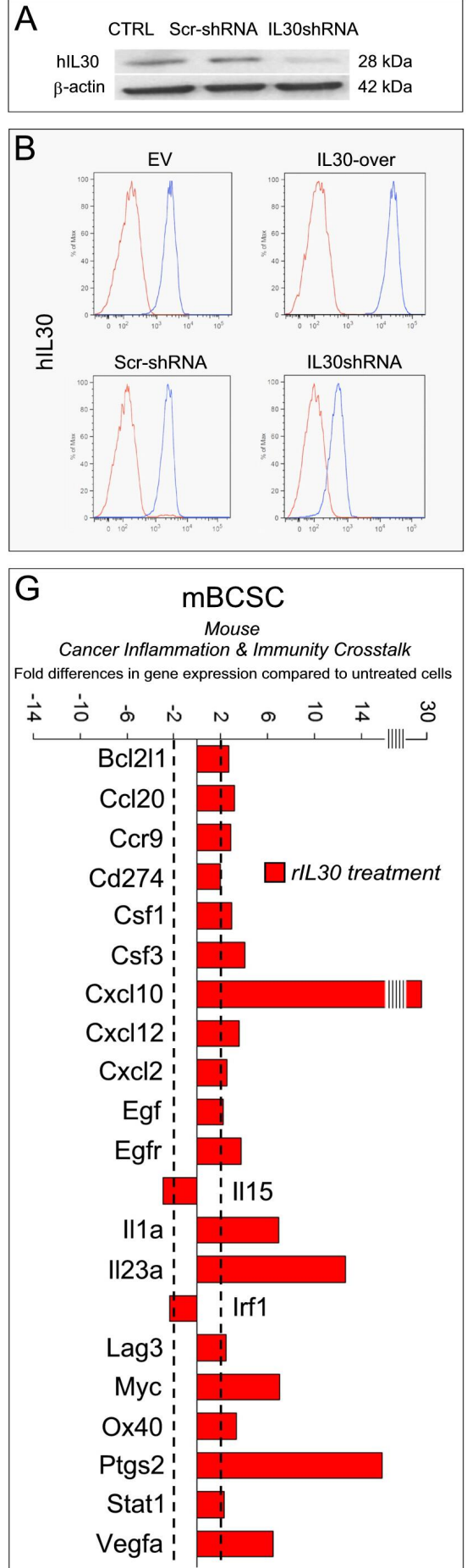
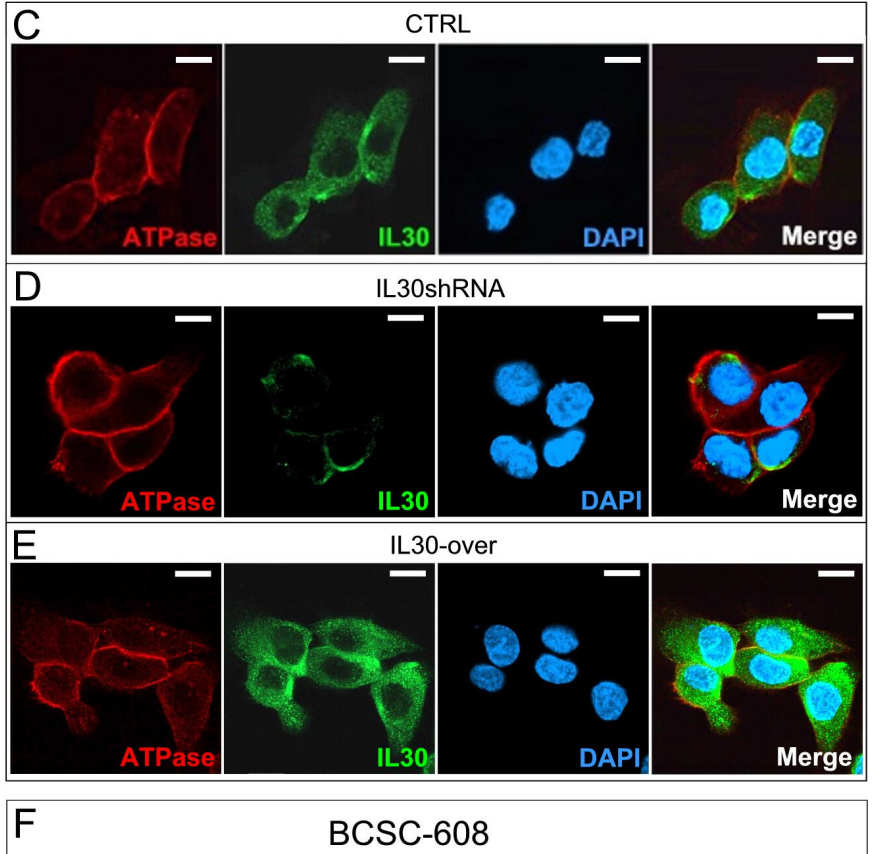

Human

Cancer Inflammation \& Immunity Crosstalk

Fold differences in gene expression compared to control cells

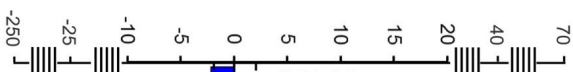

CCL4

CCL5

CCR2

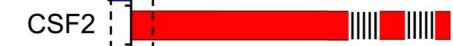

CXCL1

CXCL10

CXCL8

CXCL11

CXCR2

CXCR4

HLA-A

IL10

IL12A

IL15

IIIIII |||||

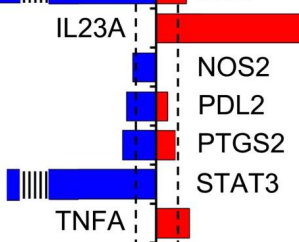

Figure 2 IL30-dependent regulation of the immunity gene expression in breast cancer stem cells (BCSCs). (A) Western blot analyses of IL30 protein expression in wild-type (CTRL), IL30shScrRNA and IL30shRNA transfected BCSC-608 cells. (B) Flow cytometric analysis of IL30 expression on the cell membrane of EV and IL30-over, ScrRNA and IL30shRNA transfected BCSC-608 cells. Results from untransfected BCSC-608 cells are comparable with those from EV and IL30shScrRNA transfected cells. (C-E) Confocal microscopy images of IL30 expression (green) that co-localizes with the red-stained $\mathrm{Na}^{+} \mathrm{K}^{+}$-ATPase in wild-type (CTRL) (C), IL30-silenced (shRNA) (D) and IL30-overexpressing (IL30-over) (E) BCSC-608. DAPI: DNA-stained nuclei. Magnification: $\times 400$. Scale bars: $6 \mu \mathrm{m}$. (F) Fold differences of mRNAs of human inflammation and immunity-related genes between IL30shRNA-transfected and ScrRNA-transfected BCSC-608 (blue bars) and between IL30 gene-transfected and EV-transfected BCSC-608 (red bars). Results from ScrRNA-transfected and EV-transfected cells are comparable with those from untransfected wild-type cells. Pooled results $\pm S D$ are from two experiments performed in duplicate. A significant threshold of 2-fold change in gene expression corresponded to $p<0.001$. (G) Fold differences of mRNAs of murine inflammation and immunity genes between //30 gene-transfected and EV-transfected mBCSCs. Results from EV-transfected cells are comparable with those from untransfected wild-type cells. Pooled results $\pm S D$ are from two experiments performed in duplicate. A significant threshold of 2-fold change in gene expression corresponded to $p<0.001$. 
$\mathrm{EV}$, and $3.33 \pm 1.40 \mathrm{pg} / \mathrm{mL}$ in CTRL cells. ANOVA: $\mathrm{p}=0.009$; Tukey HSD test: $\mathrm{p}<0.05$ versus both $\mathrm{EV}$ and CTRL cells).

To compare the response of hBCSCs to IL30 with that of its murine counterpart, which will be useful in vivo in the immunocompetent model, the immunity gene expression profile was also analysed in mBCSCs after rIL30 treatment (figure 2G).

In mBCSCs, rIL30 upregulated Stat1 (2.31 times), Bcl2-like protein 1 (Bcl2ll) (2.69 times) and Myc (7.04 times), and boosted the expression of a set of genes coding for growth factors, such as Csf1 (2.93 times), Csf3 (4.04 times), Vegfa (6.50 times), $E g f$ (2.21 times), Egfr (3.78 times) and inflammatory mediators, such as Illa (6.94 times) and, especially, Il23a (12.68 times) and Ptgs2 (15.78 times), whereas $I l 15$ and IrfI were downregulated (-2.90 and -2.38 times, respectively).

Recombinant IL30 also stimulated mBCSC expression of chemokines and their receptors, such as Ccr9 (2.89 times), Ccl20 (3.22 times), Cxcl2 (2.54 times), Cxcl12 (3.56 times) and particularly Cxcl10 (27.47 times), along with expression of immune checkpoint molecules $C d 274 / P d-l 1$ (2.02 times), $\operatorname{Lag} 3$ (2.46 times) and $O x 40$ (3.33 times).

Comparative analysis of human and murine IL30-driven transcriptional profiles revealed a common and substantial upregulation of CXCLIO and IL23A, which prompted us to assess their role in IL30-dependent regulation of BCSC viability.

\section{CXCL10 and IL23 autocrine loops mediate IL30-dependent proliferation of BCSCs}

IL30-induced upregulation of CXCL10 and IL23 in human and murine BCSCs, led us to investigate their production and functional consequences.

The treatment of mBCSC cells with rIL30 (50 ng/ $\mathrm{mL}, 48$ hours) stimulated the production and release of CXCL10 (105.90 $11.20 \mathrm{pg} / \mathrm{mL}$ versus $69.60 \pm 5.73 \mathrm{pg} /$ $\mathrm{mL}$ in untreated cells; Student's t-test: $\mathrm{p}=0.02$ ). At concentrations ranging from 30 to $150 \mathrm{ng} / \mathrm{mL}$, CXCL10 significantly increased the proliferation of both mBCSCs (ANOVA: $\mathrm{p}<0.0001$; Tukey HSD test: $\mathrm{p}<0.05$ ) (figure $3 \mathrm{~A}$ ) and mBC cell line E0771 (ANOVA: $\mathrm{p}<0.0001$; Tukey HSD test: $\mathrm{p}<0.01$ ) (figure $3 \mathrm{~B}$ ), a TN cell line isolated from a mammary tumor developed in a female mouse with the identical genetic background of mBCSCs. Both cell lines expressed the CXCL10 receptor, CXCR3 (figure 3C).

The increased proliferation of mBCSCs induced by rIL30 or the supernatant obtained from IL30mBCSCs (IL30sup) was significantly inhibited, although not abolished, by the addition of anti-CXCL10 Abs (ANOVA: $\mathrm{p}<0.0001$; Tukey HSD test: $\mathrm{p}<0.05$ ) (figure 3D), which strongly suggests the existence of an autocrine loop triggered by IL30-induced CXCL10.

Treatment of mBCSCs with rIL30 $(50 \mathrm{ng} / \mathrm{mL})$ also stimulated the production and release of IL23 $(75.10 \pm 13.71 \mathrm{pg} /$ $\mathrm{mL}$ versus $53.26 \pm 6.19 \mathrm{pg} / \mathrm{mL}$ in untreated cells; Student's t-test $\mathrm{p}=0.04$ ). However, although both mBCSCs and mBC cells expressed the IL12R $\beta 1$ (online supplemental figure S3), neither cell lines expressed the IL23R (figure 3E), ${ }^{32}$ which indicates that, at least in the mouse model, only paracrine effects can be expected by IL30-induced IL23.

CXCR3, specifically the isoforms CXCR3-A and CXCR3-B (figure 3F,G,H,I), and IL23R (figure 3J) were expressed by hBCSCs, and the treatment with rCXCL10 or rIL23 $(5-100 \mathrm{ng} / \mathrm{mL})$ significantly increased both their proliferation (ANOVA: $\mathrm{p}<0.01$ ) (figure $3 \mathrm{~K}, \mathrm{~L}, \mathrm{M}$ and $\mathrm{N}$ ) and their mammosphere formation efficiency (rCXCL10 treated BCSC-608, $\mathrm{p}<0.0001, \chi^{2}$ test versus CTRL; rCXCL10 treated BCSC-105, $\mathrm{p}=0.0029, \chi^{2}$ test versus CTRL; rIL23 treated BCSC-608, $\mathrm{p}<0.0001, \chi^{2}$ test versus CTRL; rIL23 treated BCSC-105, $\mathrm{p}=0.0044, \chi^{2}$ test versus $\mathrm{CTRL}$ ) (figure $3 \mathrm{O}, \mathrm{P}, \mathrm{Q}$ and $\mathrm{R}$ ).

ELISA revealed that both BCSC-608 and BCSC-105 constitutively released CXCL10 $(23.86 \pm 1.31 \mathrm{pg} / \mathrm{mL}$ and $4411.40 \pm 62.98 \mathrm{pg} / \mathrm{mL}$, respectively), but not IL23.

IL30 overexpression by IL30 gene transfected BCSC-608 dramatically increased the production (figure $4 \mathrm{~A}$ ) and release of CXCL10 (IL30-over: $28.64 \pm 0.53 \mathrm{pg} / \mathrm{mL}$, versus EV: $23.41 \pm 0.60 \mathrm{pg} / \mathrm{mL}$, and CTRL cells: $23.86 \pm 1.31 \mathrm{pg} /$ $m L$; ANOVA: $p=0.0006$; Tukey HSD test: $p<0.01$ versus both EV and CTRL cells) and induced the production (figure 4B) and release of IL23 (IL30-over: $8.89 \pm 1.28 \mathrm{pg}$ / $\mathrm{mL}$, versus EV and CTRL cells: $0.00 \mathrm{pg} / \mathrm{mL}$ ).

IL30 overexpression by IL30 gene transfected BCSC105 also increased the production (figure 4C) and release of CXCL10 (IL30-over: $4738.63 \pm 15.75 \mathrm{pg}$ / $\mathrm{mL}$, versus $\mathrm{EV}: 4406.82 \pm 68.30 \mathrm{pg} / \mathrm{mL}$, and CTRL cells: $4411.40 \pm 62.98 \mathrm{pg} / \mathrm{mL}$; ANOVA: $\mathrm{p}=0.0004$; Tukey HSD test: $\mathrm{p}<0.01$ versus both EV and CTRL), while IL23 was undetectable (online supplemental figure S4).

The addition of neutralizing anti-CXCL10 Abs (0.5$1.0 \mu \mathrm{g} / \mathrm{mL})$ or anti-IL23 Abs $(0.5-1.0 \mu \mathrm{g} / \mathrm{mL})$ to the culture medium of IL30-overexpressing BCSC-608 significantly (ANOVA: $\mathrm{p}<0.001$ ) inhibited IL30-dependent cell proliferation (figure $4 \mathrm{D}, \mathrm{E}$ ). At a concentration of $0.5 \mu \mathrm{g} /$ $\mathrm{mL}$, the anti-CXCL10 Abs reduced, but did not abolished, the proliferative effect induced by IL30 overexpression, and the combination with anti-IL23 Abs brought the proliferation back to CTRL levels. (figure 4F).

As observed in wild-type BCSC-608 (figure 4D), neutralizing anti-CXCL10 Abs $(0.5-1.0 \mu \mathrm{g} / \mathrm{mL})$ decreased the proliferation of wild-type BCSC-105, since they constitutively released the chemokine, and significantly (ANOVA: $\mathrm{p}<0.0001$ ) suppressed the proliferation of IL30overexpressing BCSC-105 (figure 4G), thus strengthening the role of the CXCL10-triggered autocrine loop in mediating IL30-induced BCSC proliferation.

\section{IL30 overproduction by BCSCs boosts tumor growth and reduces survival in association with tumor production of CXCL10 and IL23 and infiltration by MDC, Tregs and ILC3}

The effect of IL30 overexpression by BCSCs on tumor onset and progression was investigated after orthotopic implantation of IL30mBCSCs and control clones $\left(1 \times 10^{4}\right.$ cells) in syngeneic C57BL/6 female mice. Fifteen days after their implantation, IL30mBCSCs gave rise to tumors, which grew and reached, 48 days later, a mean tumor 

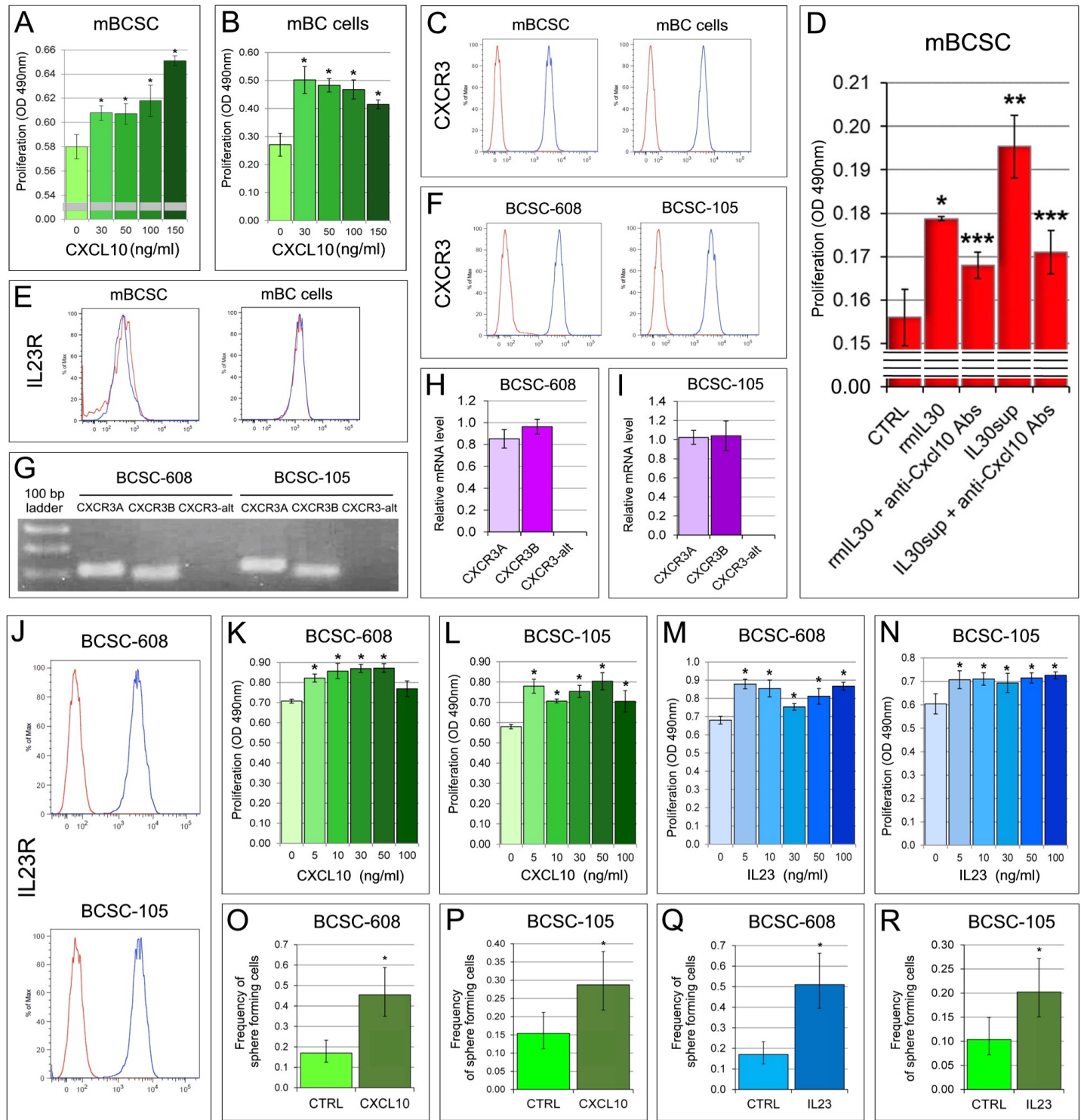

Figure 3 IL30-dependent regulation of breast cancer stem cell (BCSC) viability. (A) MTT assay of mBCSCs after 48 hours treatment with $\mathrm{rCXCL} 10$ at concentrations of $30,50,100$ and $150 \mathrm{ng} / \mathrm{mL}$. ANOVA: $p=0.00001$. ${ }^{*} p<0.05$, Tukey HSD test compared with $0 \mathrm{ng} / \mathrm{mL}$. (B) MTT assay of $\mathrm{mBC}$ cells after 48 hours of treatment with $\mathrm{rCXCL} 10$ at concentrations of 30, 50, 100 and $150 \mathrm{ng} / \mathrm{mL}$. ANOVA: $p=0.00006$. ${ }^{*} p<0.01$, Tukey HSD test compared with $0 \mathrm{ng} / \mathrm{mL}$. (C) Cytofluorimetric analyses of CXCR3 expression in mBCSCs and mBC cells. Red lines: isotype control. Blue lines: specific Abs. Experiments were performed in triplicate. (D) MTT assay of mBCSCs 48 hours after the treatment with rmIL30 $(50 \mathrm{ng} / \mathrm{mL})$, with or without antiCXCL10 Abs $(40 \mu \mathrm{g} / \mathrm{mL})$, or with IL30sup, with or without anti-CXCL10 Abs $(40 \mu \mathrm{g} / \mathrm{mL})$. ANOVA: $\mathrm{p}<0.0001 .{ }^{*} \mathrm{p}<0.01$, Tukey HSD test compared with CTRL, rmIL30 + anti-CXCL10 Abs and IL30sup. ${ }^{* *} \mathrm{p}<0.01$, Tukey HSD test compared with CTRL, rmIL30, rmIL30 + anti-CXCL10 Abs and IL30sup + anti-CXCL10 Abs. ${ }^{* *}$ p $<0.01$, Tukey HSD test compared with CTRL. (E) Cytofluorimetric analyses of IL23R expression in mBCSCs and mBC cells. Red lines: isotype control. Blue lines: specific Abs. Experiments were performed in triplicate. (F) Cytofluorimetric analyses of CXCR3 expression in hBCSCs. Red lines: isotype control. Blue lines: specific Abs. Experiments were performed in triplicate. (G) Expression of CXCR3 isoforms in hBCSCs, as determined by RT-PCR. CXCR3A: $111 \mathrm{bp}$; CXCR3B: $79 \mathrm{bp}$; CXCR3-alt: $135 \mathrm{bp}$. (H, l) Relative expression \pm SD of mRNA of the three CXCR3 isoforms in BCSC-608 (H) and in BCSC-105 (I). (J) Cytofluorimetric analyses of IL23R expression in hBCSCs. Red line: isotype control. Blue lines: specific Abs. Experiments were performed in triplicate. (K) MTT assay of BCSC-608 after 48 hours of treatment with $r C X C L 10$ at concentration of $5-100 \mathrm{ng} / \mathrm{mL}$. ANOVA: $p=0.00001$. ${ }^{*} p<0.01$, Tukey HSD test compared with $0 \mathrm{ng} / \mathrm{mL}$. (L) MTT assay of BCSC-105 after 48 hours of treatment with $\mathrm{rCXCL} 10$ at concentrations of 5-100 $\mathrm{ng} / \mathrm{mL}$. ANOVA: $p=0.00002$. ${ }^{*} p<0.01$, Tukey HSD test compared with $0 \mathrm{ng} / \mathrm{mL}$. (M) MTT assay of BCSC-608 after 48 hours of treatment with rlL23 at concentrations of $5-100 \mathrm{ng} / \mathrm{mL}$. ANOVA: $p=0.0000002$. ${ }^{*} p<0.01$, Tukey HSD test compared with $0 \mathrm{ng} / \mathrm{mL}$. (N) MTT assay of BCSC-105 after 48 hours of treatment with rhIL23 at concentrations of $5-100 \mathrm{ng} / \mathrm{mL}$. ANOVA: $p=0.0028$. ${ }^{*} p<0.05$, Tukey HSD test compared with $0 \mathrm{ng} / \mathrm{mL}$. (O, P) Sphere-forming capacity, evaluated by ELDA, of (O) BCSC-608 (* $\mathrm{p}<0.0001, \chi^{2}$ test versus $\mathrm{CTRL}$ ) and (P) BCSC-105 ( ${ }^{*} \mathrm{p}=0.0029, \chi^{2}$ test versus CTRL) cells, after 8 days of treatment with $50 \mathrm{ng} / \mathrm{mL}$ of $\mathrm{rCXCL} 10$. (Q, R) Sphere-forming capacity, evaluated by ELDA, of (Q) BCSC-608 ( ${ }^{\star} \mathrm{p}<0.0001, \chi^{2}$ test versus CTRL) and (R) BCSC-105 ( ${ }^{\star} \mathrm{p}=0.0044$, $\chi^{2}$ test versus CTRL) cells, after 8 days of treatment with $50 \mathrm{ng} / \mathrm{mL}$ (BCSC-608) or $10 \mathrm{ng} / \mathrm{mL}$ (BCSC-105) of rlL23. 

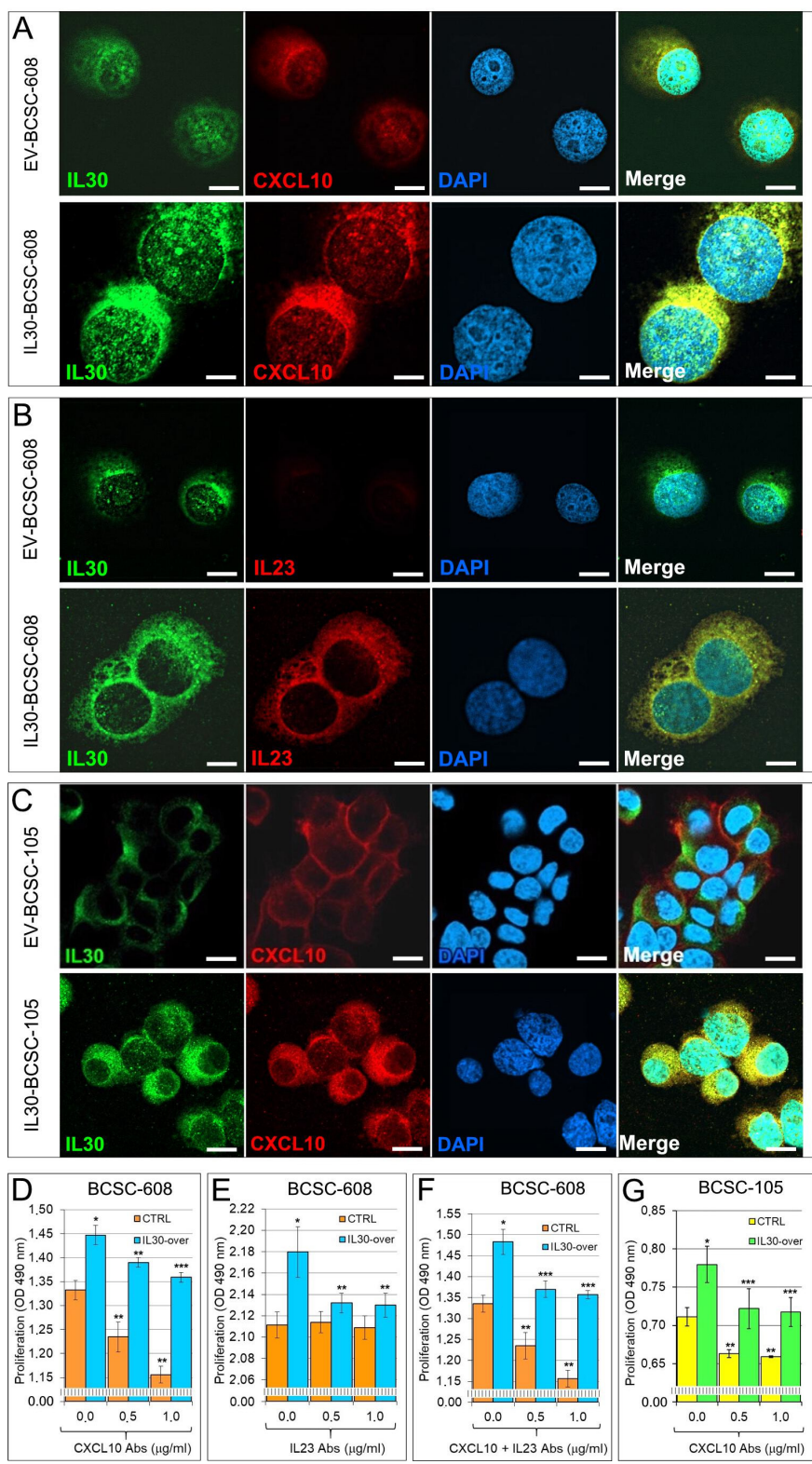

Figure 4 IL30-dependent production of CXCL10 and IL23 in breast cancer stem cells (BCSCs) and related autocrine loops. (A) Confocal microscopy images of IL30 (green) and CXCL10 (red) in EV and IL30 gene transfected BCSC-608 cells. DAPI: DNA-stained nuclei. Magnification EV-BCSC-608: ×630; IL30-BCSC-608: ×1000. Scale bars EV-BCSC-608: $6 \mu$ m; IL30BCSC-608: $3 \mu \mathrm{m}$. (B) Confocal microscopy images of IL30 (green) and IL23 (red) in EV and IL30 gene transfected BCSC-608 cells. DAPI: DNA-stained nuclei. Magnification EV-BCSC-608: ×630; IL30-BCSC-608: ×1000. Scale bars EV-BCSC-608: $6 \mu \mathrm{m}$; IL30-BCSC-608: $3 \mu \mathrm{m}$. (C) Confocal microscopy images of IL30 (green) and CXCL10 (red) in EV and IL30 gene transfected BCSC-105 cells. DAPI: DNA-stained nuclei. Magnification: $\times 630$. Scale bars: $6 \mu \mathrm{m}$. (D) MTT assay of IL30-overexpressing (light blue bars) or wild-type (CTRL, orange bars) BCSC-608 cells, treated with different concentrations of anti-CXCL10 Abs. ANOVA: $p<0.0001 .{ }^{*} p<0.01$, Tukey HSD test compared with untreated CTRL cells. ${ }^{* *} p<0.05$ Tukey HSD test compared with untreated CTRL and IL30-overexpressing cells. ${ }^{* \star *} \mathrm{p}<0.01$ Tukey HSD test compared with untreated IL30-overexpressing cells. Results obtained from EV-transfected cells were comparable with those from CTRL cells. (E) MTT assay of IL30-overexpressing (light blue bars) or wild-type (CTRL, orange bars) BCSC-608 cells, treated with different concentrations of anti-IL23 Abs. ANOVA: $p<0.01$. ${ }^{*} p<0.01$, Tukey HSD test compared with untreated CTRL cells. ${ }^{* *} p<0.05$ Tukey HSD test compared with untreated IL30overexpressing cells. Results obtained from EV-transfected cells were comparable with those from CTRL cells. (F) MTT assay of IL30-overexpressing (light blue bars) or wild-type (CTRL, orange bars) BCSC-608 cells, treated with different concentrations of anti-CXCL10 and anti-IL23 Abs. ANOVA: $p<0.0001$. ${ }^{*} p<0.01$, Tukey HSD test compared with untreated CTRL cells. ${ }^{* *} p<0.01$ Tukey HSD test compared with untreated CTRL and IL30-overexpressing cells. ${ }^{* \star *} \mathrm{p}<0.01$ Tukey HSD test compared with untreated IL30-overexpressing cells. Results obtained from EV-transfected cells were comparable with those from CTRL cells. (G) MTT assay of IL30-overexpressing (light green bars) or wild-type (CTRL, yellow bars) BCSC-105 cells, treated with different concentrations of anti-CXCL10 Abs. ANOVA: $p<0.0001 .{ }^{*} p<0.01$, Tukey HSD test compared with untreated CTRL cells. ${ }^{* *} p<0.05$ Tukey HSD test compared with untreated CTRL and IL30-overexpressing cells. ${ }^{* \star *} \mathrm{p}<0.05$ Tukey HSD test compared with untreated IL30-overexpressing cells. Results obtained from EV-transfected cells were comparable with those from CTRL cells. 
volume (MTV) significantly higher than control tumors (MTV of IL30mBCSC tumors: $671.66 \pm 158.95 \mathrm{~mm}^{3}$; MTV of EVmBCSC tumors: $160.31 \pm 56.34 \mathrm{~mm}^{3}$; MTV of mBCSC tumors: $164.50 \pm 58.90 \mathrm{~mm}^{3}$; ANOVA: $\mathrm{p}<0.0001$; Tukey HSD test: $\mathrm{p}<0.01$; figure $5 \mathrm{~A}$ ).

The survival of mice bearing IL30-overexpressing tumors was significantly lower (log-rank test: $p<0.0001)$ than that of control tumor-bearing mice (figure 5B). Both EV-derived and mBCSC-derived tumors recapitulated the histologic and immunophenotypic features $\left(\mathrm{E}^{-c a d h e r i n}{ }^{+}, \mathrm{CK}^{+}, \mathrm{CK}_{1} 4^{+}, \mathrm{ER}^{-}\right.$and $\mathrm{PR}^{-}, \mathrm{HER} 2^{\text {low }}$ ) of the $\mathrm{BC}$ from which the cells were isolated (online supplemental figure S5) ${ }^{21}{ }^{33}$ By contrast, tumors developed after implantation of IL30mBCSCs were poorly differentiated (figure 5C a,b), and expressed IL30 (figure 5C, c,d) and stemness genes, especially Myc (which is upregulated by IL30, both in vitro, figure $2 \mathrm{G}$, and in vivo, figure $5 \mathrm{D}$, a,b; IL30mBCSC tumors, $81.56 \% \pm 7.38 \%$; EVmBCSC tumors, $49.20 \% \pm 7.15 \%$; mBCSC tumors, $46.6 \% \pm 4.55 \%$; ANOVA: $p<0.0001$; Tukey HSD test: $p<0.01$, IL30mBCSC tumors versus $\mathrm{EVmBCSC}$ and $\mathrm{mBCSC}$ tumors) and Klf4 (figure 5D c,d; IL30mBCSC tumors, $76.33 \% \pm 6.67 \%$; EVmBCSC tumors, $53.67 \% \pm 8.49 \%$; mBCSC tumors, $51.89 \% \pm 3.52 \%$; ANOVA: $\mathrm{p}<0.001$; Tukey HSD test: $\mathrm{p}<0.01$, IL30mBCSC tumors versus EVmBCSC and mBCSC tumors; figure $5 \mathrm{E} ; 10.32$ times upregulation of Klf4 in vitro), which, along with Snai2 (2.48 times), Zeb1 (3.61 times) and Zeb2 (3.01 times), were upregulated also in mBCSCs treated with rIL30 (figure 5E). IL30-overexpressing tumors were highly proliferating (IL30mBCSC tumors, $83.00 \% \pm 6.56 \%$; EVmBCSC tumors, $48.78 \% \pm 4.84 \%$; mBCSC tumors, $49.00 \% \pm 3.20 \%$; ANOVA: $\mathrm{p}<0.0001$; Tukey HSD test: $\mathrm{p}<0.01$, IL30mBCSC tumors versus $\mathrm{EVmBCSC}$ and $\mathrm{mBCSC}$ tumors) and well vascularized (MVD: IL30mBCSC tumors, 14.13 \pm 2.64 ; EVmBCSC tumors, 7.11 \pm 1.76 ; mBCSC tumors, $6.44 \pm 1.51$; ANOVA: $\mathrm{p}<0.0001$; Tukey HSD test: $\mathrm{p}<0.01$, IL30mBCSC tumors versus $\mathrm{EVmBCSC}$ and $\mathrm{mBCSC}$ tumors; figure $5 \mathrm{C}, \mathrm{e}-\mathrm{h}$ ). Genes that were the most upregulated by IL30 in BCSCs, including Cxc110 and IL23, were strongly expressed also by IL30-overexpressing tumors (figure $5 \mathrm{C}, \mathrm{i}-1$ ), which were heavily infiltrated by $\mathrm{F} 4 / 80^{+}$macrophages, $\mathrm{CD} 11 \mathrm{~b}^{+} \mathrm{Gr}-1^{+}$ myeloid derived cells (MDC), Ly- $6 \mathrm{G}^{+}$granulocytes, Foxp $^{+} \mathrm{T}$ regulatory (Tregs) cells and NKp $46^{+} \mathrm{ROR} \gamma \mathrm{t}^{+}$ type 3 innate lymphoid cells (ILC3) (figure 5F,G). This immune cell population mostly co-localised with intratumoral expression of IL22 and IL17 (figure 5H).

\section{IL30 overproduction by BCSCs promotes their survival in the bloodstream and seeding in the lung, increasing the incidence of metastases, which recapitulate the immune contexture of the primary tumors}

The most common sites of metastasis for $\mathrm{BC}$ are the bones and lungs. ${ }^{34}$ IL30 has proven to boost tumor progression ${ }^{4}$ 1218 and this article and to favor bone marrow and lung colonization. ${ }^{4}$ In the present model of BCSCs, in which the lung is the main site of metastasis, ${ }^{19}$ to investigate the effects of IL30 on the different metastatic phases, we compared spontaneous versus experimental metastasis.

Although the number of mice which developed metastases was not significantly different between mice bearing EV, or wild-type, tumors and mice bearing IL30overexpressing tumors $(18 / 30$ versus $24 / 30)$, the latter developed an average number of lung metastases (mets) that was significantly higher than in control tumor-bearing mice (average number of 9 mets/mouse developed from IL30mBCSC tumors versus 2 mets/mouse from mBCSC and EVmBCSC tumors; ANOVA: $\mathrm{p}<0.0001$; Tukey HSD test: $\mathrm{p}<0.01$; figure $6 \mathrm{~A}$ ). The number of metastases per mouse did not correlate with the tumor size, as determined by Pearson's correlation coefficient $(r=0.0137)$.

Inflammatory microenvironment and immune contexture of lung metastasis (figure 6B, a,b) were consistent with the immunopathologic features of the primary tumors. Indeed, metastasis which developed from IL30overexpressing tumors showed higher proliferation index (mean percentage $\pm \mathrm{SD}$ of PCNA-positive cells/number of total cells per field: IL30mBCSC tumors, $77.33 \% \pm 7.99 \%$ ) than metastasis from control tumors (EVmBCSC tumors, $36.75 \% \pm 6.30 \%$; mBCSC tumors, $37.25 \% \pm 7.92 \%$; ANOVA: $\mathrm{p}<0.0001$; Tukey HSD test: $\mathrm{p}<0.01$ versus both controls) (figure 6B, c,d) and a prominent expression of CXCL10 and IL23 (figure 6B, e-h). Metastases developed from IL30-overexpressing tumors were heavily infiltrated by

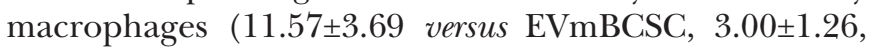
and mBCSC, $3.83 \pm 1.47)$, Foxp3 ${ }^{+}$Tregs $(9.44 \pm 3.28$ versus EVmBCSC: $2.11 \pm 1.17$ and mBCSC: $3.00 \pm 1.41$ ) (figure 6B, $\mathrm{i}, \mathrm{j})$ and NKp46 ${ }^{+} \mathrm{ROR}_{\mathrm{t}}{ }^{+}$ILC3 (12.67 \pm 4.18 versus EVmBCSC, $3.70 \pm 1.42$, and mBCSC, $4.10 \pm 2.13$ ) (ANOVA: $p<0.0001$; Tukey HSD test: $\mathrm{p}<0.01$ versus both controls) (figure $6 \mathrm{~B}$, $k, l$, and magnification in figure $6 \mathrm{C} \mathrm{a}$ ), which expanded under the pleura, and bronchial mucosa (figure 6C, b). Experimental metastasis experiments revealed that $100 \%$ $(30 / 30)$ of mice intravenously injected with IL30mBCSCs developed lung metastasis (average number of 1.7 metastasis/mouse) versus only $27 \%(8 / 30)$ of mice injected with EVmBCSCs, and 33\% (10/30) of mice injected with mBCSCs (average number of 1.5 metastasis/mouse) (Fisher's exact test, $\mathrm{p}<0.0001$; figure 6D). The immunopathological characteristics were comparable with those found in spontaneous metastases. These findings suggest that IL30 produced by BCSCs supports their survival in the bloodstream and favors their extravasation and proliferation in the lungs.

\section{Expression of IL30 in clinical BC samples correlates with that of CXCL10 and IL23, which are prevalent in TNBC}

To evaluate whether the induction of CXCL10 and IL23, by IL30, in BCSCs may have clinical-pathological implications, we analysed RNA-sequencing data of tumor samples obtained from 1084 patients with BC, included in the "Breast Invasive Carcinoma TCGA PanCancer collection" published by the Cancer Genome ATLAS (TCGA) Consortium ${ }^{27}$ Bioinformatics revealed that expression of 

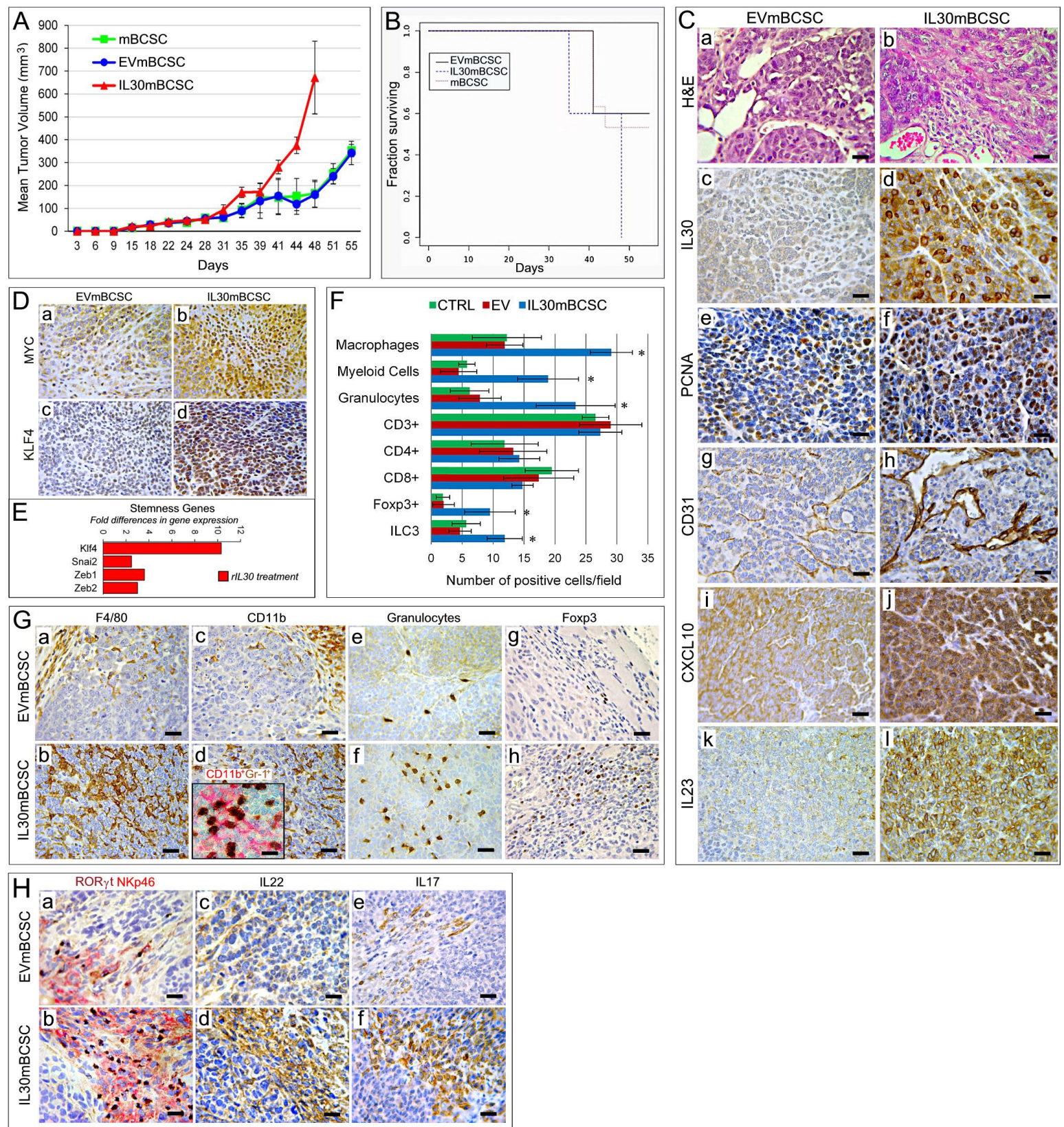

Figure 5 Growth rate and immune contexture of tumors developed after orthotopic implantation of IL30-overexpressing mBCSCs in syngeneic host. (A) Mean volume of tumors developed after orthotopic implantation of IL30mBCSCs, EVmBCSCs or wild-type mBCSCs. ANOVA, $p<0.0001$; Tukey HSD test, $p<0.01$ versus both controls. (B) Kaplan-Meier survival curves of mice bearing tumors developed after orthotopic implantation of IL3OmBCSCs, EVmBCSCs or mBCSCs. Log-rank test: $p=0.000024$. (C) H\&E-stained sections (a, b) and immunopathological features (c-l) of tumors developed after orthotopic implantation of EVmBCSCs or IL30mBCSCs in syngeneic mice. Histology and immunopathology of tumors induced by mBCSCs were comparable with those induced by EVmBCSCs. Magnification: $\times 400$. Scale bars: $20 \mu \mathrm{m}$. (D) Expression of MYC and KLF4 in tumors induced by EV (a, c) and I/30 gene transfected (b, d) mBCSCs. Magnification: $\times 400$. Scale bars: $20 \mu \mathrm{m}$. (E) Fold differences of mRNAs of stemness-related genes between IL30mBCSCs and EVmBCSCs. Results obtained from EVmBCSCs are comparable with those from wild-type CTRL cells. Pooled results $\pm S D$ are from two experiments performed in duplicate. A significant threshold of 2 -fold change in gene expression corresponded to $p<0.001$. (F) Automated immune cell count in tumors developed after implantation of IL30mBCSCs, EVmBCSCs (EV) or mBCSCs (CTRL) in syngeneic mice, assessed by immunohistochemistry, as described in Methods section. ANOVA: $p<0.001 .{ }^{*} p<0.01$, Tukey HSD test compared with EV and CTRL. (G) Immune cell contexture of tumors developed after orthotopic implantation of IL30mBCSCs reveals a greater content of $\mathrm{F} 4 / 80^{+}$macrophages $(\mathrm{a}, \mathrm{b}), \mathrm{CD} 11 \mathrm{~b}^{+}$cells (c, d; red stained in the inset) mostly co-expressing Gr-1 (brown stained in the inset), $\mathrm{Ly}_{-} 6 \mathrm{G}^{+}$granulocytes (e, f) and Foxp3 ${ }^{+}$Tregs $(\mathrm{g}, \mathrm{h})$ than control tumors. Magnification: $\times 400$; inset in d: $\times 630$. Scale bars: $20 \mu \mathrm{m}$; inset in d: $10 \mu \mathrm{m}$. (H) Double staining with anti-ROR $\gamma$ (brown) and anti-NKp46 (red) Abs revealed that, unlike control tumors (a), tumors induced by IL3OmBCSCs (b) were heavily infiltrated by NKp $46^{+}$cells endowed with ROR $\mathrm{Rt}^{+}$ nuclei, indicative of ILC3. Intratumoral expression of IL22 (c, d) and IL17 (e, f) was localized in the areas infiltrated by ILC3. Magnification: $\times 400$. Scale bars: $20 \mu \mathrm{m}$. 


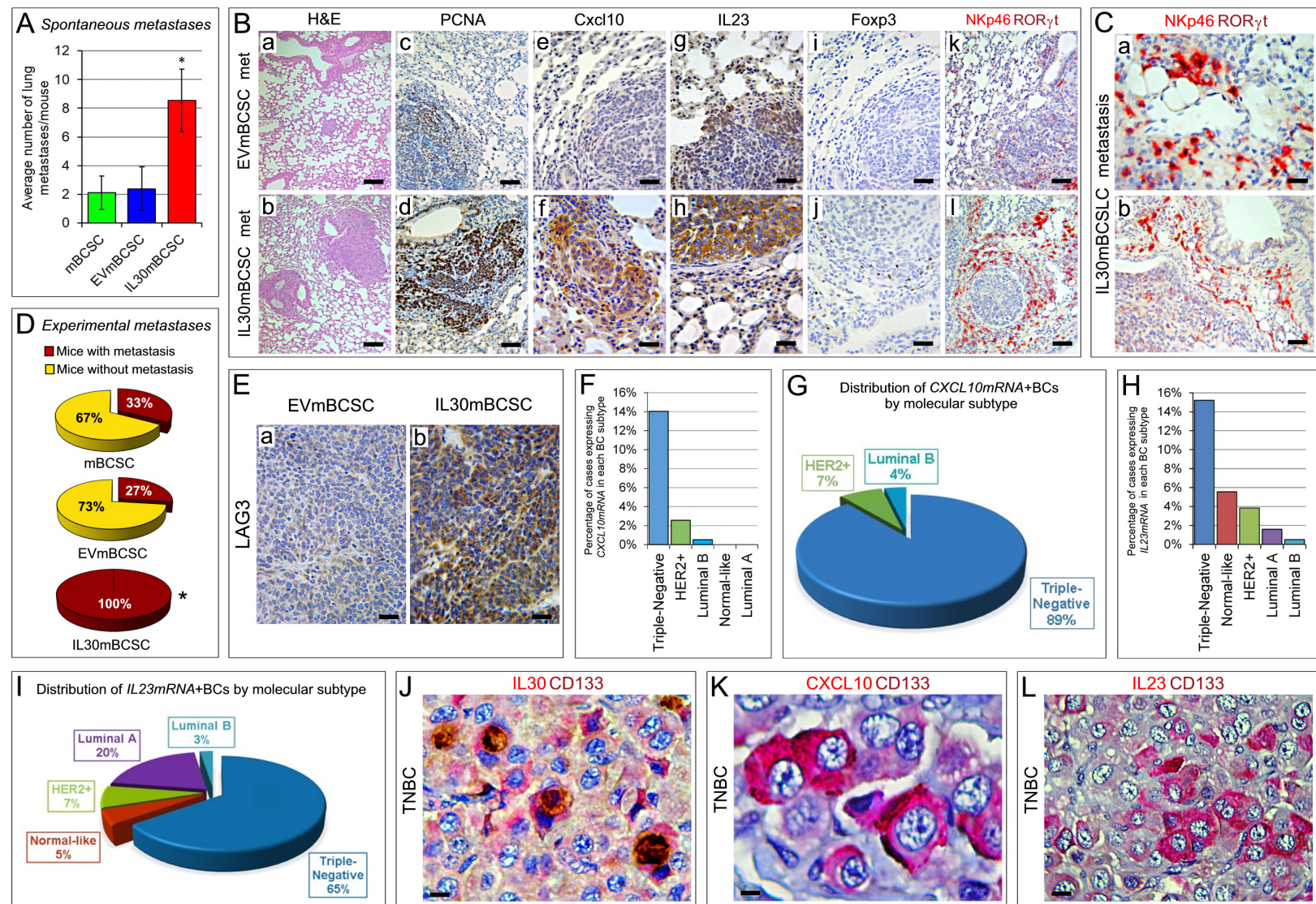

Figure 6 Immune microenvironment of lung metastasis induced by IL30-overexpressing mBCSCs and expression of IL30induced secondary mediators, CXCL10 and IL23, in human breast cancers (BCs). (A) Average number of lung metastasis per mouse spontaneously developed from tumors induced by IL30mBCSCs, EVmBCSCs or wild-type mBCSCs. ANOVA: $p<0.0001$; Tukey HSD test: $p<0.01$ versus both controls. (B) Histopathological features and immune contexture of lung metastasis spontaneously developed from tumors induced by IL30mBCSC and EVmBCSC implantation in syngeneic mice. Magnification: a, b, k, I, $\times 200$; c-j: $\times 400$. Scale bars a, b, k, l: $30 \mu \mathrm{m} ; \mathrm{c}-\mathrm{j}: 20$ m. (C) In lung metastasis developed from IL30-overexpressing tumors, ILC3 infiltrate extends under the pleura (a, detail of figure B, I) and bronchial mucosa (b). Magnification a: ×630; b: $\times 200$. Scale bars a: $10 \mu \mathrm{m}$; B: $30 \mu \mathrm{m}$. (D) Percentage of mice which developed lung metastasis 40 days after intravenous injection of IL30mBCSCs, EVmBCSCs or mBCSCs. *Fisher's exact test, $p<0.0001$ versus both controls. (E) Immunohistochemical analysis of LAG3 expression in tumors developed after orthotopic implantation of EV-mBCSCs (a) and IL30mBCSCs (b) in syngeneic mice. Magnification: $\times 400$. Scale bars: $20 \mu \mathrm{m}$. (F) CXCL10mRNA expression in human BC subtypes from the PanCancer cohort. The histogram represents the percentage of CXCL10mRNA overexpressing cases (Z-score $>2$ ) out of the total number of cases for each $\mathrm{BC}$ subtype. (G) Distribution of $\mathrm{CXCL} 10^{+} \mathrm{BCs}$ by molecular subtypes, represented as percentage of the total number of BC expressing CXCL10mRNA. (H) IL23mRNA expression in human BC subtypes from the PanCancer cohort. The histogram represents the percentage of IL23 overexpressing cases (Z-score $>2$ ) out of the total number of cases for each BC subtype. (I) Distribution of $I L 23^{+} \mathrm{BCs}$ by molecular subtypes, represented as percentage of the total number of BC expressing IL23mRNA. (J) Double immunostaining of TNBC tissues showing IL30 (red) co-localization with $\mathrm{CD}_{133^{+}}$(brown) cancer cells. Magnification: $\times 630$. Scale bar: $10 \mu \mathrm{m}$. (K) Double immunostaining of TNBC tissues showing CXCL10 (red) co-localization with CD133 ${ }^{+}$ (brown) cancer cells. Magnification: $\times 1000$. Scale bar: $6 \mu \mathrm{m}$. (L) Double immunostaining of TNBC tissues showing IL23 (red) colocalization with $\mathrm{CD}_{133^{+}}$(brown) cancer cells. Magnification: $\times 630$. Scale bar: $10 \mu \mathrm{m}$.

IL30mRNA was associated with Triple-Negative $\mathrm{BC},{ }^{18}$ the subtype with the highest $\mathrm{CD} 133^{+}$stem cell content. ${ }^{19}{ }^{35}$

Since TNBC is the most represented BC subtype (26 out of 75 cases) in the database developed by Waddell $e t$ $a l,{ }^{36}$ included in the Oncomine Platform (https://www. oncomine.org), we performed an outlier analysis of gene expression data from this sample collection, using the Cancer Outlier Profile Analysis (COPA) algorithm, which revealed that IL30 expression ranked beyond the $95^{\text {th }}$ percentile and, therefore, it was in the top 5\% (COPA score $=16.727$ ) of the most expressed genes.
Profiling of tumor infiltrating immune cells, by using CIBERSORTx computational method (http://cibersort. stanford.edu/), revealed that the median percentage of both naive and memory resting $\mathrm{CD} 4^{+} \mathrm{T}$ cells, $\gamma \delta \mathrm{T}$ cells and resting dendritic cells (DCs) was significantly lower in IL30 highly expressing (IL30 ${ }^{\text {high }}$ ) BC samples (calculated after the exclusion of cases that also overexpressed EBI3, Z-score $\geq 1$, to avoid effects due to IL27) versus IL30 low expressing (IL30 ${ }^{\text {low }}$ ) BCs (online supplemental table S6). Profiling of immune exhaustion markers, which include immune checkpoint molecules (online supplemental 
table S7), performed to test the functional status of tumor-infiltrating immune cells, revealed a significantly higher expression of LAG3 in M1 macrophages infiltrating IL $30^{\text {high }}$ BCs (1.67-fold), compared with the corresponding cell population in IL30 ${ }^{\text {low }}$ BCs (Student's t-test: $\mathrm{p}=0.0121$ ). This finding is consistent with the upregulation of LAG3 by IL30 treatment in mBCSCs (figure 2G) and mTNBC cells, ${ }^{18}$ and with its production, by cancer and infiltrating immune cells in IL30-overexpressing murine tumors (figure 6E, a,b).

Analysis of gene expression profiles, provided by the PanCancer dataset, also revealed a significant association between the expression of CXCL1OmRNA and TNBC (Fisher's exact test, $\mathrm{p}<0.05$ versus HER2 ${ }^{+}$, Normal-like, Luminal A and Luminal B) (figure 6F). CXCL10mRNA expression was detected in $89 \%$ of TN, $7 \%$ of HER2 ${ }^{+}$and $4 \%$ of Luminal B (figure 6G). A significant association was also found between the expression of IL23AmRNA and TNBC (Fisher's exact test, $\mathrm{p}<0.01$ versus HER2 ${ }^{+}$, Luminal $\mathrm{A}$ and Luminal B) (figure 6H). IL23AmRNA expression involved $65 \%$ of TN, $7 \%$ of HER2 ${ }^{+}, 20 \%$ of Luminal A, $5 \%$ of Normal-like, and 3\% of Luminal B (figure $6 \mathrm{I}$ ).

Bioinformatic analyses revealed a positive correlation, by Spearman's rank correlation coefficient, between the expression of IL30 and that of CXCL10 ( $\rho=0.493)$, and $I L 23 A(\rho=0.313)$. Furthermore, the expression of CXCL10 was positively correlated to that of IL23A $(\rho=0.421)$. Immunostaining confirms, in TNBC samples, the production of IL30 in CD133 ${ }^{+}$BCSCs (figure 6J) and the frequent co-expression of CXCL10 $(58.34 \% \pm 4.62 \%$, mean \pm SD of CXCL10-positive cells/total number of CD133 IL $30^{+}$ cells per field) and IL23 $(51.28 \% \pm 8.22 \%$, mean \pm SD of IL23-positive cells/total number of CD133 ${ }^{+} \mathrm{IL} 0^{+}$cells per field) (Student's t-test: $\mathrm{p}<0.00001$ ) (figure 6K,L, and online supplemental table S8), thereby supporting the finding of the role of IL30-driven cytokine circuits in BCSC behavior.

\section{DISCUSSION}

Despite therapeutic advancements, BC remains a dreadful disease, estimated to cause 655,690 deaths worldwide this year. ${ }^{1}$ Leading causes of BC-related deaths are tumor recurrence and metastasis, which are driven by self-renewing and multipotent BCSCs, highly resistant to current therapies. ${ }^{23}$ The balance between quiescence, proliferation and differentiation of CSCs is regulated by paracrine, autocrine and contact-dependent signals. ${ }^{37}$ Here, we provide evidence that IL30 affects directly, and via second-level mediators, BCSC behavior and immune contexture. Cancer SCs isolated from human BCs are unable to release IL30 or IL27, but constitutively express IL30 as a membrane-anchored glycoprotein and alteration of its expression levels, by enforced overexpression or silencing, dramatically increases, or inhibits, respectively, their viability and self-renewal efficiency, and subverts their immunity gene expression profile. The lack of IL30 in the supernatant of hIL30 gene transfected
hBCSCs is consistent with data reported by Pflanz and coworkers, ${ }^{6}$ who failed to detect hIL30 protein in the supernatant of hHEK293 cells, after transfection with hp28, whereas transfection with the murine counterpart resulted in protein secretion.

Since alteration of IL30 protein levels, by gene transfection, localized neither in the cytoplasm nor in the supernatant, but in the plasma membrane, the functional outcomes are likely due to juxtacrine signals activated by a membrane-bound bioactive IL30. The blockade of these contact-dependent signals, by anti-IL30 neutralizing Abs, hinders proliferation and self-renewal of hBCSCs, suggesting IL30's ability to control the maintenance and expansion of the CSC compartment. Therefore, IL30 enters the group of human membrane-anchored cytokines, which includes IL1 $\alpha,{ }^{38}$ IL15, ${ }^{39}$ M-CSF, ${ }^{40}$ Flt3 ligand, ${ }^{41}$ TNF $\alpha,{ }^{42} \mathrm{LT} \alpha,{ }^{43}$ Fractalkine $/ \mathrm{CX} 3 \mathrm{CL} 1,{ }^{44} \mathrm{TGF} \beta{ }^{45}$ and IFN $\gamma,{ }^{46}$ that have demonstrated biological effects via the juxtacrine route, under physiological conditions. Signaling through cell-cell contact, IL30 overexpressed by hBCSCs triggers a storm of inflammatory mediators, including IL1 $\beta$, TNF $\alpha$, CCL4, CXCL8, CXCL10 and, especially, CSF2/GM-CSF, CXCL1, IL23A and CXCL10. By contrast, silencing of the IL30 gene downregulates tumor-promoting factors, such as CCL28, CCL5, CCR2, CXCR2, CXCR4, NOS2, PDL2, PTGS2 and, especially, IL1 $\beta$ and STAT3, which is functional to IL30 signaling in TNBC cells. ${ }^{15}$ TNBC has the highest BCSC content ${ }^{19}$ and the most frequent expression of IL30. ${ }^{15}$ Targeting IL30 in the host environment has proven effective against TNBC progression. ${ }^{18}$ Analyses of TNBCs developed in IL30 knocked out mice after implantation of IL30 responsive or unresponsive (ie, with or without IL30R) TNBC cells provided an opportunity to analyze the effects of IL30 on the tumor immune contexture. ${ }^{518}$ Regardless of the induction of CXCL10, IL23 or other mediators in tumor cells, endogenous IL30 prevents the intratumoral recruitment of $\mathrm{CD}^{+} \mathrm{T}, \mathrm{CD} 4^{+} \mathrm{T}$ and $\mathrm{NKp} 46^{+}$cells, along with IFN $\gamma$ production, and favors the influx of immunosuppressive $\mathrm{IDO}^{+}$MDCs, macrophages and Tregs. By contrast, the lack of endogenous IL30 prevents the expansion of $\mathrm{IL} 10^{+} \mathrm{CD} 4^{+} \mathrm{CD} 25^{+} \mathrm{Foxp} 3^{+}$ Tregs, during tumor growth, whereas it favors intratumoral T-cell infiltration, mainly of $\mathrm{CD} 4^{+} \mathrm{T}$ lymphocytes, and cytotoxic functions. These data could explain why, despite IL30 induces in tumor cells CXCL10, which has been reported to recruit activated CXCR3 ${ }^{+}$Th1 cells, ${ }^{47}$ IL30-overexpressing tumors lack enrichment in T lymphocytes.

Unlike the human counterpart, mIL30 is efficiently released by $I l 30$ gene transfected mBCSCs, as a soluble mediator. Similarly to the human cytokine, mIL30 promotes the proliferation and self-renewal of mBCSCs, and fosters their expression of oncogenes Bcl211 and Myc, and a range of immune regulatory factors, such as Ccl20, Csf3, Cxcl12 and, particularly, Ptgs2, Vegfa, Cxcl10 and Il23, most of which are also induced by IL30 in murine and human TNBC cells. ${ }^{1518}$

Human and murine IL30-associated immune gene signatures share a substantial upregulation of CXCL10 
and IL23. Both molecules are secreted by BCSCs in response to IL30 and mediate most of the IL30-dependent proliferation and self-renewal, which are suppressed by their selective blockade, suggesting novel autocrine loops that foster CSCs and can be disrupted by targeting IL30 signaling. In hBCSCs, IL30 overexpression also promotes the release of CSF2 and CXCL1. Despite being used for its immune adjuvant function, ${ }^{48}$ when produced by BC, CSF2 has revealed immunosuppressive and tumorpromoting effects, and positive correlation with a worst clinical outcome. ${ }^{49}{ }^{50}$ CXCL1 has been recently demonstrated to sustain proliferation and self-renewal of BCSCs, and to regulate their transcriptional profile, by promoting tumor progression and immune escape programs. ${ }^{51}$

Orthotopic implantation, in immune-competent host, of BCSCs engineered to release IL30 provides novel insight into the tumor-promoting functions of this cytokine. IL30 overexpression by mBCSCs accelerates tumor growth and reduces host survival, in association with an increased cancer proliferation, vascularization and expression of stemness genes, including MYC and KLF4, which play a key role in the maintenance of BCSCs. ${ }^{16} 52$ CXCL10 and IL23 were produced by IL30-overexpressing tumors, which were heavily infiltrated by macrophages, MDCs, granulocytes, Tregs and ILC3. In addition to CXCL10 and IL23, a wide range of IL30-induced proinflammatory factors could account for this immune cell context, in particular, CSF3/G-CSF, IL1 $\alpha$, VEGF and PTGS2, which are the most upregulated.

G-CSF can modulate the tumor microenvironment, by promoting angiogenesis and granulocyte, macrophage and MDSC recruitment. ${ }^{53}$ IL1 $\alpha$ recruits neutrophils, ${ }^{54}$ favors angiogenesis, ${ }^{55}$ and promotes the expansion of BCSCs and metastasis. ${ }^{56} 57$ Tumor hyperproduction of VEGFA fosters endothelial cell proliferation and vascular leakage favoring leukocyte extravasation, but also inhibits functional maturation of $\mathrm{DC}^{58}$ and promotes immature myeloid cell recruitment. ${ }^{58}$

High levels of COX2 and PGE2 by tumor cells directly recruit Tregs and contribute to $\mathrm{CD} 8^{+} \mathrm{T}$ lymphocyte apoptosis in murine BC. ${ }^{59}$

CXCL10 exhibits pleiotropic function in tumor biology since its interaction with CXCR3-A leads to tumor cells survival and proliferation, whereas interaction with CXCR3-B mediates anti-proliferative, pro-apoptotic and angiostatic effects. ${ }^{60}$ In BC, overexpression of CXCR3-B has demonstrated to enhance the sphere-forming potential of CSC and to amplify their compartment, which is depleted by CXCR3-B silencing. ${ }^{61}$ Here, we demonstrated that mBCSCs are endowed with CXCR3, and hBCSCs express isoforms $\mathrm{A}$ and $\mathrm{B}$, and that both cell lines respond to CXCL10 by increasing their proliferation and sphereforming ability. Originally identified as a chemoattractant of $\mathrm{CXCR}^{+}$leukocytes, including macrophages, dendritic and NK cells and activated T lymphocytes, ${ }^{62}$ CXCL10 has been shown to also recruit Tregs ${ }^{63}$ and increase transcription of T-bet and ROR $\gamma t$, leading to the polarization of $\operatorname{Tr} 1$ and Th17 from naive T cells. ${ }^{64}$ Thereby, CXCL10 released by IL30-stimulated BCSCs may contribute in shaping their immune contexture, which is enriched in Tregs and NKp $46^{+}{ }^{+}$OR $\gamma \mathrm{t}^{+}$ILC3. ILC3 co-localizes with IL22 and IL17, which fuel an immunosuppressive environment. ${ }^{6566}$ Produced by IL30-overexpressing tumors, IL23 can lead to the expansion of ILC ${ }^{67}$ and enable their expression of IL17 and IL22. ${ }^{67}$ Although their role in cancer is yet to be clarified, ILC3 promote LN metastasis in $\mathrm{BC}^{68}$ and in NSCLC their percentage has been associated with IL23 expression in tumor cells and with short patient survival. ${ }^{69}$ Expression of IL23p19 is frequent in human tumors and it has been demonstrated to boost angiogenesis and innate inflammatory influx, while inhibiting $\mathrm{CD} 8^{+} \mathrm{T}$ cell infiltrate, thus promoting tumor growth. ${ }^{70}$ In patients with BC, serum level of IL23 correlates with shorter overall survival and its overexpression with BCSC proliferation. ${ }^{7172}$ Hyperproliferation, along with the considerable production of IL23 and CXCL10, observed in the context of murine IL30-positive tumors, was also found in spontaneous and experimental metastasis induced by IL30-overexpressing BCSCs. Although the metastatic propensity of mBCSC $^{21}$ does not allow to detect a difference in the number of mice which develop metastasis, between those bearing IL30-negative and IL30-positive tumors, the latter develop more metastasis per mouse and have reduced survival. The greater number of metastatic cases among mice receiving intravenous inoculation of IL30-overexpressing BCSCs versus control cells indicates that IL30 supports CSC survival in the bloodstream, extravasation and engraftment in the lung, where the immune contexture mirrors that of spontaneous metastasis and their primary tumors. Bioinformatic evidence of a correlation between the expression of IL30 and that of CXCL10 and IL23 in human BC tissues, and their prevalence in TNBCs, in which IL30 ${ }^{+}$BCSCs frequently co-express CXCL10 and IL23, supports the translational value of our finding and emphasizes the pathobiological role of the IL30-driven inflammatory cascade in BC behavior. Since IL30 has been found in the top 5\% of the most expressed genes in the TN enriched BC collection, ${ }^{36}$ it can be argued that the IL30-driven tumor-promoting circuit may be of relevance in the pathobiology and evolution of the most aggressive forms of BC.

The CIBERSORTx algorithm provided new information on the immune profile associated with IL30 overexpression in the $\mathrm{BC}$ microenvironment, by revealing a lower content in $\gamma \delta \mathrm{T}$ cells, and a defective infiltrate of naïve and memory resting $\mathrm{CD} 4^{+} \mathrm{T}$ cells and DCs, in IL30 ${ }^{\text {high }}$ compared with IL30 $0^{\text {low }}$ BCs.

Intratumoral $\gamma \delta \mathrm{T}$ cells emerged as the most significant favorable cancer-wide prognostic population ${ }^{73}$ and have been associated with remission in TNBC subtype. ${ }^{74}$ However, their role is controversial, ${ }^{75}$ possibly due to the heterogeneity of the $\mathrm{BC}$ microenvironment that, depending on the immune contexture, oncogenic signaling and cytokine milieu, can polarize $\gamma \delta \mathrm{T}$ cells toward an anti-tumoral or pro-tumoral phenotype. ${ }^{77} 78$ The question of whether the IL $30^{\text {low }}$ TME can shape cytotoxic 
effector $\gamma \delta$ T-cell subsets endowed with anti-tumor activity is yet to be investigated, as well as the biological and prognostic value of its naive and memory resting $\mathrm{CD} 4^{+} \mathrm{T}$ and DC infiltrate.

On the other hand, expression of LAG3 in M1 macrophages, which has recently been observed also in diffuse large B-cell lymphoma, ${ }^{79}$ characterizes IL30 ${ }^{\text {high }}$ BCs, and corroborates our experimental findings, 18 and this paper providing evidence of the functional immune exhaustion associated with IL30-rich microenvironment.

In addition to providing new clues, through biostatistical investigations, of the tumor-promoting activity of IL30, our study demonstrates that BCSCs express membrane-bound IL30, which sustains their expansion directly and via second-level cytokines, mainly, CXCL10 and IL23. These immune regulatory factors mediate autocrine proliferative and self-renewal loops, but also contribute, together with the other second-level mediators, to the IL30-associated immune microenvironment. Targeting the IL30 pathway is a valuable strategy to restrain the BCSC compartment and to counteract immune suppression and $\mathrm{BC}$ progression.

\section{Author affiliations}

'Department of Medicine and Sciences of Aging, "G. d'Annunzio" University" of Chieti-Pescara, Chieti, Italy

${ }^{2}$ Anatomic Pathology and Immuno-Oncology Unit, Center for Advanced Studies and Technology (CAST), "G. d'Annunzio" University of Chieti-Pescara, Chieti, Italy ${ }^{3}$ Department of Health Promotion Sciences, Internal Medicine and Medical Specialties, University of Palermo, Palermo, Italy

Contributors EDC conceived the study. CS, SLC, LD'A, PL and CF performed the experiments, collected and assembled the data. EDC, CS and SLC performed data analyses. AT and MT provided human BCSCs. EDC interpreted the data and wrote the manuscript. All authors read and approved the final manuscript.

Funding The research leading to these results has received funding from AIRC, under IG 2019 - ID. 23264 project - P.I. Di Carlo Emma and IG 2018 - ID. 14415 project - P.I. Todaro Matilde, and from the Italian Ministry of University and Research (PRIN - 2017M8YMR8 - Unit 3 P.I. Di Carlo Emma).

Competing interests None declared.

\section{Patient consent for publication Not applicable.}

Ethics approval Animal procedures were performed in accordance with the European Community guidelines and were approved by the Institutional Animal Care Committee of the "G. d'Annunzio" University and by the Italian Ministry of Health (Authorization n. 892/2018-PR). The study on human tissue samples was performed in accordance with the principles outlined in the Declaration of Helsinki and approved by the Ethical Committee of the "G. d'Annunzio" University and Local Health Authority of Chieti, Italy (Protocol ONCO-2017-1, 04/19/2018). Informed consent to participate in the study was obtained from the participants.

Provenance and peer review Not commissioned; externally peer reviewed.

Data availability statement Data are available on reasonable request. All data generated or analysed during this study are available from the corresponding author on reasonable request.

Supplemental material This content has been supplied by the author(s). It has not been vetted by BMJ Publishing Group Limited (BMJ) and may not have been peer-reviewed. Any opinions or recommendations discussed are solely those of the author(s) and are not endorsed by BMJ. BMJ disclaims all liability and responsibility arising from any reliance placed on the content. Where the content includes any translated material, BMJ does not warrant the accuracy and reliability of the translations (including but not limited to local regulations, clinical guidelines, terminology, drug names and drug dosages), and is not responsible for any error and/or omissions arising from translation and adaptation or otherwise.
Open access This is an open access article distributed in accordance with the Creative Commons Attribution Non Commercial (CC BY-NC 4.0) license, which permits others to distribute, remix, adapt, build upon this work non-commercially, and license their derivative works on different terms, provided the original work is properly cited, appropriate credit is given, any changes made indicated, and the use is non-commercial. See http://creativecommons.org/licenses/by-nc/4.0/.

\section{ORCID iDs}

Cristiano Fieni http://orcid.org/0000-0001-7203-6545

Emma Di Carlo http://orcid.org/0000-0001-7778-1042

\section{REFERENCES}

1 Ferlay J, Colombet M, Soerjomataram I, et al. Estimating the globa cancer incidence and mortality in 2018: GLOBOCAN sources and methods. Int J Cancer 2019;144:1941-53.

2 Dittmer J. Breast cancer stem cells: features, key drivers and treatment options. Semin Cancer Biol 2018;53:59-74.

3 Bai X, Ni J, Beretov J, et al. Cancer stem cell in breast cancer therapeutic resistance. Cancer Treat Rev 2018;69:152-63.

4 Sorrentino C, Ciummo SL, Cipollone G, et al. Interleukin-30/IL27p28 shapes prostate cancer stem-like cell behavior and is critical for tumor onset and metastasization. Cancer Res 2018;78:2654-68.

5 Sorrentino C, Yin Z, Ciummo S, et al. Targeting interleukin(IL)-30/ IL-27p28 signaling in cancer stem-like cells and host environment synergistically inhibits prostate cancer growth and improves survival. $J$ Immunother Cancer 2019;7:201.

6 Pflanz S, Timans JC, Cheung J, et al. IL-27, a heterodimeric cytokine composed of EBI3 and p28 protein, induces proliferation of naive CD4+ T cells. Immunity 2002;16:779-90.

7 Canale S, Cocco C, Frasson C, et al. Interleukin-27 inhibits pediatric B-acute lymphoblastic leukemia cell spreading in a preclinical model. Leukemia 2011;25:1815-24.

8 Di Carlo E, Sorrentino C, Zorzoli A, et al. The antitumor potential of interleukin-27 in prostate cancer. Oncotarget 2014:5:10332-41.

9 Airoldi I, Tupone MG, Esposito S, et al. Interleukin-27 re-educates intratumoral myeloid cells and down-regulates stemness genes in non-small cell lung cancer. Oncotarget 2015;6:3694-708.

10 Garbers C, Hermanns HM, Schaper F, et al. Plasticity and crosstalk of interleukin 6-type cytokines. Cytokine Growth Factor Rev 2012;23:85-97.

11 Liu X, Wang Z, Ye N, et al. A protective role of IL-30 via STAT and ERK signaling pathways in macrophage-mediated inflammation. Biochem Biophys Res Commun 2013;435:306-12.

12 Di Carlo E. Decoding the role of interleukin-30 in the crosstalk between cancer and myeloid cells. Cells 2020;9:615.

13 Garbers C, Spudy B, Aparicio-Siegmund S, et al. An interleukin-6 receptor-dependent molecular switch mediates signal transduction of the IL-27 cytokine subunit p28 (IL-30) via a gp130 protein receptor homodimer. J Biol Chem 2013;288:4346-54.

14 Di Meo S, Airoldi I, Sorrentino C, et al. Interleukin-30 expression in prostate cancer and its draining lymph nodes correlates with advanced grade and stage. Clin Cancer Res 2014;20:585-94.

15 Airoldi I, Cocco C, Sorrentino C, et al. Interleukin-30 promotes breast cancer growth and progression. Cancer Res 2016;76:6218-29.

16 Yang A, Qin S, Schulte BA, et al. MYC inhibition depletes cancer stem-like cells in triple-negative breast cancer. Cancer Res 2017;77:6641-50.

17 Riobo-Del Galdo NA, Lara Montero Ángela, Wertheimer EV. Role of Hedgehog signaling in breast cancer: pathogenesis and therapeutics. Cells 2019;8:375.

18 Sorrentino C, Ciummo SL, D'Antonio L, et al. Hindering triple negative breast cancer progression by targeting endogenous interleukin-30 requires IFN $\gamma$ signaling. Clin Trans/ Med 2021;11:e278.

19 Park SY, Choi JH, Nam JS. Targeting cancer stem cells in triplenegative breast cancer. Cancers 2019;11:965.

20 Todaro M, Turdo A, Bartucci M, et al. Erythropoietin activates cell survival pathways in breast cancer stem-like cells to protect them from chemotherapy. Cancer Res 2013;73:6393-400.

21 Bao L, Cardiff RD, Steinbach P, et al. Multipotent luminal mammary cancer stem cells model tumor heterogeneity. Breast Cancer Res 2015; $17: 137$.

22 Casey AE, LASTER WR, Ross GL. Sustained enhanced growth of carcinoma EO771 in C57 black mice. Proc Soc Exp Biol Med 1951;77:358-62.

23 Johnstone CN, Smith YE, Cao Y, et al. Functional and molecular characterisation of EO771.LMB tumours, a new C57BL/6-mousederived model of spontaneously metastatic mammary cancer. Dis Model Mech 2015;8:237-51. 
$24 \mathrm{Hu}$ Y, Smyth GK. ELDA: extreme limiting dilution analysis for comparing depleted and enriched populations in stem cell and other assays. J Immunol Methods 2009;347:70-8.

25 Faul F, Erdfelder E, Buchner A, et al. Statistical power analyses using $\mathrm{G}^{*}$ Power 3.1: tests for correlation and regression analyses. Behav Res Methods 2009;41:1149-60.

26 Rosner B. Fundamentals of biostatistics. 7th edn. Boston, MA: Brooks/Cole, 2011.

27 Berger AC, Korkut A, Kanchi RS, et al. A comprehensive pan-cancer molecular study of gynecologic and breast cancers. Cancer Cell 2018;33:690-705.

28 Newman AM, Steen CB, Liu CL, et al. Determining cell type abundance and expression from bulk tissues with digital cytometry. Nat Biotechnol 2019;37:773-82

29 Newman AM, Liu CL, Green MR, et al. Robust enumeration of cell subsets from tissue expression profiles. Nat Methods 2015;12:453-7.

30 Müller SI, Friedl A, Aschenbrenner I, et al. A folding switch regulates interleukin 27 biogenesis and secretion of its $\alpha$-subunit as a cytokine. Proc Natl Acad Sci U S A 2019;116:1585-90.

31 Morth JP, Pedersen BP, Buch-Pedersen MJ, et al. A structural overview of the plasma membrane $\mathrm{Na}+, \mathrm{K}+-\mathrm{ATP}$ ase and $\mathrm{H}+$-ATPase ion pumps. Nat Rev Mol Cell Biol 2011;12:60-70.

32 Parham C, Chirica M, Timans J, et al. A receptor for the heterodimeric cytokine IL-23 is composed of IL-12Rbeta1 and a novel cytokine receptor subunit, IL-23R. J Immunol 2002;168:5699-708.

33 Biswas T, Gu X, Yang J, et al. Attenuation of TGF- $\beta$ signaling supports tumor progression of a mesenchymal-like mammary tumor cell line in a syngeneic murine model. Cancer Lett 2014;346:129-38.

34 Jin L, Han B, Siegel E, et al. Breast cancer lung metastasis: molecular biology and therapeutic implications. Cancer Biol Ther 2018;19:858-68.

35 Park SY, Lee HE, Li H, et al. Heterogeneity for stem cell-related markers according to tumor subtype and histologic stage in breast cancer. Clin Cancer Res 2010;16:876-87.

36 Waddell N, Cocciardi S, Johnson J, et al. Gene expression profiling of formalin-fixed, paraffin-embedded familial breast tumours using the whole genome-DASL assay. J Pathol 2010;221:452-61.

37 Yang L, Shi P, Zhao G, et al. Targeting cancer stem cell pathways for cancer therapy. Signal Transduct Target Ther 2020;5:8.

38 Kurt-Jones EA, Fiers W, Pober JS. Membrane interleukin 1 induction on human endothelial cells and dermal fibroblasts. J Immunol 1987;139:2317-24.

39 Musso T, Calosso L, Zucca M, et al. Human monocytes constitutively express membrane-bound, biologically active, and interferongamma-upregulated interleukin-15. Blood 1999;93:3531-9.

40 Cerretti DP, Wignall J, Anderson D, et al. Human macrophage-colony stimulating factor: alternative RNA and protein processing from a single gene. Mol Immunol 1988;25:761-70.

41 Lyman SD, James L, Escobar S, et al. Identification of soluble and membrane-bound isoforms of the murine FLT3 ligand generated by alternative splicing of mRNAs. Oncogene 1995;10:149-57.

42 Kriegler M, Perez C, DeFay K, et al. A novel form of TNF/cachectin is a cell surface cytotoxic transmembrane protein: ramifications for the complex physiology of TNF. Cell 1988;53:45-53.

43 Browning JL, Ngam-ek A, Lawton P, et al. Lymphotoxin beta, a novel member of the TNF family that forms a heteromeric complex with lymphotoxin on the cell surface. Cell 1993;72:847-56.

44 Bazan JF, Bacon KB, Hardiman G, et al. A new class of membranebound chemokine with a CX3C motif. Nature 1997;385:640-4.

45 Nakamura K, Kitani A, Strober W. Cell contact-dependent immunosuppression by CD4(+)CD25(+) regulatory T cells is mediated by cell surface-bound transforming growth factor beta. $J$ Exp Med 2001;194:629-44.

46 Assenmacher M, Scheffold A, Schmitz J, et al. Specific expression of surface interferon-gamma on interferon-gamma producing $T$ cells from mouse and man. Eur J Immunol 1996;26:263-7.

47 Lee J-H, Kim B, Jin WJ, et al. Pathogenic roles of CXCL10 signaling through CXCR3 and TLR4 in macrophages and T cells: relevance for arthritis. Arthritis Res Ther 2017;19:163.

48 Pardoll DM. Paracrine cytokine adjuvants in cancer immunotherapy. Annu Rev Immunol 1995;13:399-415.

49 Ghirelli C, Reyal F, Jeanmougin M, et al. Breast cancer cell-derived GM-CSF licenses regulatory Th2 induction by plasmacytoid predendritic cells in aggressive disease subtypes. Cancer Res 2015;75:2775-87.

50 Su S, Liu Q, Chen J, et al. A positive feedback loop between mesenchymal-like cancer cells and macrophages is essential to breast cancer metastasis. Cancer Cell 2014;25:605-20.

51 Ciummo SL, D'Antonio L, Sorrentino C, et al. The C-X-C motif chemokine ligand 1 sustains breast cancer stem cell self-renewal and promotes tumor progression and immune escape programs. Front Cell Dev Biol 2021;9:689286.

$52 \mathrm{Yu} \mathrm{F,} \mathrm{Li} \mathrm{J,} \mathrm{Chen} \mathrm{H,} \mathrm{et} \mathrm{al.} \mathrm{Kruppel-like} \mathrm{factor} 4$ (KLF4) is required for maintenance of breast cancer stem cells and for cell migration and invasion. Oncogene 2011;30:2161-72.

53 Liu L, Liu Y, Yan X, et al. The role of granulocyte colony-stimulating factor in breast cancer development: a review. Mol Med Rep 2020;21:2019-29.

54 Rider P, Carmi Y, Guttman O, et al. IL-1 $\alpha$ and IL-1 $\beta$ recruit different myeloid cells and promote different stages of sterile inflammation. $J$ Immunol 2011;187:4835-43.

55 Voronov E, Carmi Y, Apte RN. The role IL-1 in tumor-mediated angiogenesis. Front Physiol 2014;5:114.

56 Liu S, Lee JS, Jie C, et al. HER2 overexpression triggers an IL1 $\alpha$ proinflammatory circuit to drive tumorigenesis and promote chemotherapy resistance. Cancer Res 2018;78:2040-51.

57 Kuan EL, Ziegler SF. A tumor-myeloid cell axis, mediated via the cytokines IL- $1 \alpha$ and TSLP, promotes the progression of breast cancer. Nat Immunol 2018;19:366-74.

58 Gabrilovich DI, Chen HL, Girgis KR, et al. Production of vascular endothelial growth factor by human tumors inhibits the functional maturation of dendritic cells. Nat Med 1996;2:1096-103.

59 Karavitis J, Hix LM, Shi YH, et al. Regulation of COX2 expression in mouse mammary tumor cells controls bone metastasis and PGE2induction of regulatory T cell migration. PLoS One 2012;7:e46342.

60 Billottet C, Quemener C, Bikfalvi A. CXCR3, a double-edged sword in tumor progression and angiogenesis. Biochim Biophys Acta 1836;2013:287-95

61 Kundu N, Ma X, Brox R, et al. The chemokine receptor CXCR3 isoform $B$ drives breast cancer stem cells. Breast Cancer 2019;13:1178223419873628.

62 Kuo PT, Zeng Z, Salim N, et al. The role of CXCR3 and its chemokine ligands in skin disease and cancer. Front Med 2018;5:271

63 Redjimi N, Raffin C, Raimbaud I, et al. CXCR3+ T regulatory cells selectively accumulate in human ovarian carcinomas to limit type I immunity. Cancer Res 2012;72:4351-60.

64 Zohar Y, Wildbaum G, Novak R, et al. CXCL11-dependent induction of FOXP3-negative regulatory T cells suppresses autoimmune encephalomyelitis. J Clin Invest 2014;124:2009-22.

65 Lim C, Savan R. The role of the IL-22/IL-22R1 axis in cancer. Cytokine Growth Factor Rev 2014;25:257-71.

66 Zhao J, Chen X, Herjan T, et al. The role of interleukin-17 in tumo development and progression. J Exp Med 2020;217:e20190297.

67 Bal SM, Golebski K, Spits H. Plasticity of innate lymphoid cell subsets. Nat Rev Immunol 2020;20:552-65.

68 Irshad S, Flores-Borja F, Lawler K, et al. ROR $\mathrm{tt}^{+}$innate lymphoid cells promote lymph node metastasis of breast cancers. Cancer Res 2017;77:1083-96.

69 Koh J, Kim HY, Lee Y, et al. IL23-producing human lung cancer cells promote tumor growth via conversion of innate lymphoid cell 1 (ILC1) into ILC3. Clin Cancer Res 2019;25:4026-37.

70 Langowski JL, Zhang X, Wu L, et al. IL-23 promotes tumour incidence and growth. Nature 2006;442:461-5.

71 Gangemi S, Minciullo P, Adamo B, et al. Clinical significance of circulating interleukin-23 as a prognostic factor in breast cancer patients. J Cell Biochem 2012;113:2122-5.

72 Kars MD, Yıldıım G. Determination of the target proteins in chemotherapy resistant breast cancer stem cell-like cells by protein array. Eur J Pharmacol 2019;848:23-9.

73 Gentles AJ, Newman AM, Liu CL, et al. The prognostic landscape of genes and infiltrating immune cells across human cancers. Nat Med 2015;21:938-45.

$74 \mathrm{Wu}$ Y, Kyle-Cezar F, Woolf RT, et al. An innate-like $\mathrm{V} \delta 1^{+} \gamma \delta \mathrm{T}$ cell compartment in the human breast is associated with remission in triple-negative breast cancer. Sci Transl Med 2019;11:eaax9364.

$75 \mathrm{Ma} \mathrm{C}$, Zhang Q, Ye J, et al. Tumor-infiltrating $\gamma \delta \mathrm{T}$ lymphocytes predict clinical outcome in human breast cancer. $J$ Immunol 2012;189:5029-36

76 Janssen A, Villacorta Hidalgo J, Beringer DX, et al. $\gamma \delta$ T-cell receptors derived from breast cancer-infiltrating T lymphocytes mediate antitumor reactivity. Cancer Immunol Res 2020;8:530-43.

77 Park JH, Lee HK. Function of $\gamma \delta$ T cells in tumor immunology and their application to cancer therapy. Exp Mol Med 2021;53:318-27.

78 Lo Presti E, Di Mitri R, Pizzolato G, et al. $\gamma \delta$ cells and tumor microenvironment: a helpful or a dangerous liason? J Leukoc Biol 2018;103:485-92.

79 Keane C, Law SC, Gould C, et al. LAG3: a novel immune checkpoint expressed by multiple lymphocyte subsets in diffuse large B-cell lymphoma. Blood Adv 2020;4:1367-77. 